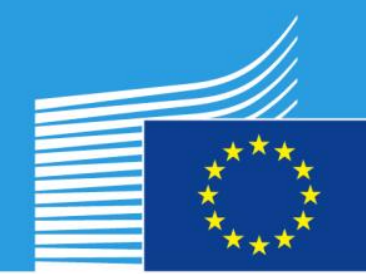

European

Commission

JRC TECHNICAL REPORTS

\title{
Do firms publish? A multi-sectoral analysis
}

JRC Working Papers on Corporate $R \& D$ and Innovation No 05/2018

Roberto Camerani, Daniele Rotolo, Nicola Grassano

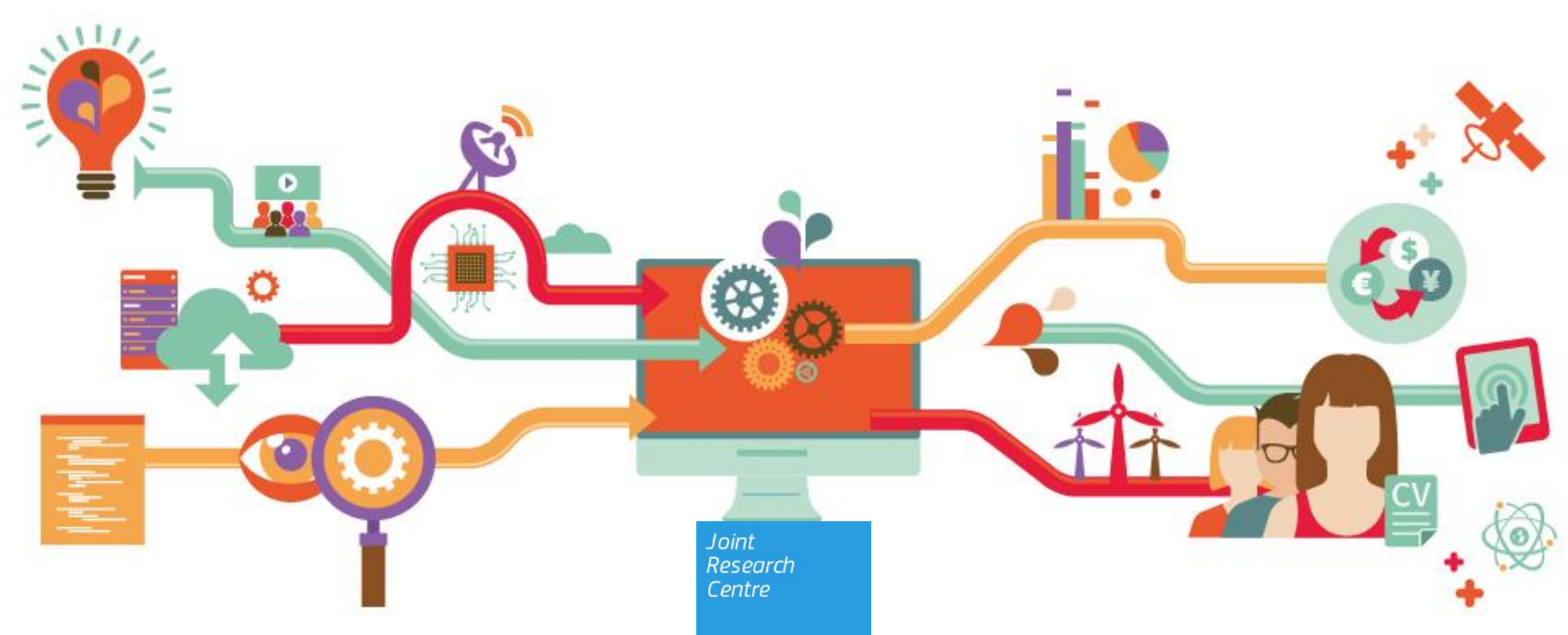


This publication is a Technical report by the Joint Research Centre (JRC), the European Commission's science and knowledge service. It aims to provide evidence-based scientific support to the European policy-making process. The scientific output expressed does not imply a policy position of the European Commission. Neither the European Commission nor any person acting on behalf of the Commission is responsible for the use which might be made of this publication.

\section{Contact information}

Antonio Vezzani

Address: Edificio Expo. c/Inca Garcilaso, 3. E-41092 Seville (Spain)

E-mail: jrc-b3-secretariat@ec.europa.eu

Tel.: +34 954488463

Fax: +34954488316

\section{JRC Science Hub}

https://ec.europa.eu/jrc

JRC113261

ISSN 1831-9408 (online)

Seville, Spain: European Commission, 2018

(C) European Union, 2018

Reproduction is authorised provided the source is acknowledged.

How to cite: Camerani, R., Rotolo, D., Grassano,n., (2018). Do firms publish? A multi-sectoral analysis, JRC Working Papers on Corporate R\&D and Innovation No 5/2018, Joint Research Centre.

All images (C) European Union 2018

The JRC Working Papers on Corporate R\&D and Innovation are published under the editorial supervision of Antonio Vezzani in collaboration with Andries Brandsma, Alex Coad, Fernando Hervás, Koen Jonkers, Pietro Moncada-Paternò-Castello, Alexander Tübke and Daniel Vertesy at the European Commission - Joint Research Centre; Michele Cincera (Solvay Brussels School of Economics and Management, Université Libre de Bruxelles); Enrico Santarelli (University of Bologna); Marco Vivarelli (Università Cattolica del Sacro Cuore, Milan).

The JRC Working Papers on Corporate R\&D and Innovation addresses economic and policy issues related to industrial research and innovation and to the competitiveness of the European industry. Mainly addressed to policy analysts and the academic community, these are policy relevant early-stage scientific articles highlighting policy implications. These working papers are meant to communicate to a broad audience preliminary research findings, generate discussion and attract critical comments for further improvements. All papers have undergone a peer review process.

This Working Paper is issued within the context of the Industrial Research, Innovation and Technology Analysis (IRITEC) project carried out by the European Commission's Joint Research Centre (Directorate B Growth \& Innovation). The IRITEC project comprises two streams: one on the territorial dimension of technology analyses (KeyTer: Key Enabling and Emerging Technologies for Territorial development and Competitiveness) and one on improving the understanding of industrial R\&D and Innovation in the EU (Gloria: GLObal Industrial Research \& Innovation Analyses). The latter is carried out jointly with the Directorate General for Research and Innovation - Directorate A, Policy Development and Coordination. 


\title{
Do firms publish?
}

\section{A multi-sectoral analysis}

\author{
Roberto Camerani $^{* 1}$, Daniele Rotolo ${ }^{\dagger 1}$, and Nicola Grassano ${ }^{\ddagger 2}$ \\ ${ }^{1}$ SPRU - Science Policy Research Unit, University of Sussex, Brighton, United Kingdom \\ ${ }^{2}$ European Commission, Joint Research Centre, Seville, Spain
}

Working paper - Version 15 October 2018

\begin{abstract}
We examine corporate publishing - i.e. firms' involvement in the production of scientific publications - with two research questions. First, why do firms publish? Through systematic literature review, we propose a framework of five incentives for firms to publish: (i) accessing external knowledge and resources; (ii) attracting and retaining researchers; (iii) signalling and reputation building; (iv) supporting IP strategies; and (v) supporting commercialization strategies. Second, how does firms' engagement in publishing differ across sectors? Variation in corporate publishing has not yet been comprehensively characterized in the literature. We present an empirical analysis of the publication activity of a global sample of 2,500 firms (and the 570,000 directly owned subsidiaries of these firms) operating in 20 industrial sectors. We find that corporate publishing is widespread, though considerable heterogeneity exists within and between sectors. Most firms (84\%) in our sample contributed to at least one publication from 2011 to 2015 . The number of firms' publications grew over the observation period (2.3\% on a yearly basis), though not as fast as the global science output in general. Firms' publications are often co-authored with researchers at academic institutions (58\%) and are cited more than expected (about 12\% of firms' articles are within the top $10 \%$ most cited articles). We conclude by proposing a taxonomy of sectors based on their R\&D investment intensity and publication activity.
\end{abstract}

Keywords: corporate publishing; incentives to publish; firm researchers; knowledge disclosure; defensive publishing; scientific publications; taxonomy

\footnotetext{
${ }^{*}$ r.camerani@sussex.ac.uk

${ }^{\dagger}$ d.rotolo@sussex.ac.uk

${ }^{\ddagger}$ nicola.grassano@ec.europa.eu
} 


\section{Introduction}

The study of the Research and Development (R\&D) process has been a core research subject in the field of science policy and innovation studies (e.g. Audretsch and Feldman, 1996; Griliches, 1979; Jaffe, 1986; Levin et al., 1987; Mansfield, 1968; Pavitt, 1984). This research interest has been mirrored by numerous policy actions to support public and private R\&D efforts as well as by initiatives aimed at producing regional, national, and global R\&D statistics to inform policymaking. ${ }^{1}$ Considerable efforts have also gone into the development of measures and indicators to characterize R\&D activities carried out by firms: financial data have been extensively used to define indicators of $R \& D$ inputs (e.g. R\&D expenditure, $R \& D$ intensity), while patent data have been adopted to characterize the output of firms' R\&D efforts.

The involvement of firms in the production of scientific publications, namely corporate publishing, has, however, received much less attention. This is despite pioneering bibliometrics studies in the 1990s providing compelling evidence that firms publish a considerable amount of their R\&D in the form of publications in scientific journals (Godin, 1996; Hicks, 1995; Hicks et al., 1994; Tijssen et al., 1996). It is true that disclosures in publications may hinder a firm's ability to capture its R\&D outcomes with other mechanisms (patents and secrecy). It is also true that publications do not ensure replicability given the high levels of tacit knowledge some discoveries or techniques may entail (Stephan, 1996) and that firms can choose what to publish while still benefiting from their R\&D efforts (Hicks, 1995).

Recent efforts focused on mapping firms' publication activity (e.g. Archambault and Larivière, 2011; Arora et al., 2018; Tijssen, 2004), developing models of a firm's decision to disclose its knowledge (e.g. Alexy et al., 2013; Baker and Mezzetti, 2005; Gans et al., 2017), proposing publication-based proxies of a firm's knowledge base and capabilities (e.g. D'Este, 2005; Gittelman and Kogut, 2003), examining the relationship between a firm's publication activity and its economic performance (e.g. Pellens and Della Malva, 2018; Simeth and Cincera, 2016), and a firm's propensity to pursue an open science strategy (e.g. Ding, 2011; Polidoro and Theeke, 2012; Simeth and Raffo, 2013) have all contributed to shed light on corporate publishing. Yet our understanding of this phenomenon is still somewhat fragmented. Limited attention has been

\footnotetext{
1 The Lisbon Strategy and the subsequent Europe 2020 Strategy with their R\&D investment targets over the European Union gross domestic product are prominent examples of the policy attention the R\&D process has received.
} 
paid to the incentives that lead firms to publish, while empirical research work has often focused on more science-oriented sectors - such as pharmaceuticals, biotechnology, and chemicals - and on samples of firms that in most of the cases were not multi-sectoral and multi-country. As a result, two key research questions have not been resolved in a systematic manner: why do firms publish? and how does firms' engagement in publishing differ across sectors?

In this paper, we first address the why do firms publish question by developing a framework of firms' incentives to publish based on a systematic review of the literature. This framework includes five categories of incentives: (i) accessing external knowledge and resources; (ii) attracting and retaining researchers; (iii) signalling and reputation building; (iv) supporting IP strategies; and (v) supporting commercialization strategies. We then address the how does firms' engagement in publishing differ across sectors question by empirically investigating the publication activity of a global sample of firms operating in 20 industrial sectors. In particular, we examine the publication activity, from 2011 to 2015 , of a sample of 2,500 top R\&D investing firms (and the 570,000 directly owned subsidiaries of these firms). The findings of this analysis provide a comprehensive map of corporate publishing in terms of the proportion of publishing firms by industrial sector; publications growth over time; impact of firms' publications (citations); firms' collaboration with academic institutions (co-authorship). Our analysis highlights that corporate publishing is not a feature of only few sectors, although considerable heterogeneity exists within and among sectors. We conclude the paper by proposing a taxonomy of sectors on the basis of sectors' intensity of $\mathrm{R} \& \mathrm{D}$ investment and publication activity.

This paper is organized as follows. Section 2 presents the theoretical background of the paper. This includes a framework of five categories of incentives for firms to publish, and provides evidence of how our understanding of the phenomenon of corporate publishing is limited to a few industrial sectors. Section 3 builds on this gap and describes the methodology we used to examine corporate publishing across 20 industrial sectors. Section 4 presents the findings of our analysis, which are then discussed in Section 5 where a taxonomy of sectors is also presented. Section 6 concludes the paper.

\section{Theoretical background}

Corporate publishing has been examined by a considerable number of studies in bibliometrics, scientometrics, science policy, economics of innvoation, and management. Research has provided 
evidence that firms do publish the outcomes of their R\&D efforts in the form of scientific publications (e.g. Archambault and Larivière, 2011; Arora et al., 2018; Furukawa and Goto, 2006; Godin, 1996; Hicks, 1995; Tijssen et al., 1996). Firm-level publication data have been also used to develop proxies of a firm's knowledge base and capabilities (e.g. D'Este, 2005; Gittelman and Kogut, 2003; Simeth and Cincera, 2016) and to estimate a firm's propensity to disclose its knowledge (e.g. Alexy et al., 2013; Baker and Mezzetti, 2005; Gans et al., 2017) or to pursue an open science strategy (e.g. Ding, 2011; Polidoro and Theeke, 2012; Simeth and Raffo, 2013). These efforts have contributed to increasing considerably our understanding of corporate publishing. But we still have limited knowledge of what incentives to publish are at work for firms, as well as of how firms' engagement in corporate publishing may differ from one sector to another. To fill this gap, we first present a framework that aims to address the why do firms publish question in a systematic manner. The framework builds on a systematic review of extant literature on corporate publishing. We then analyse this literature to provide evidence that current research has not comprehensively addressed the how does firms' engagement in publishing differ across sectors question, which we will aim to address with our empirical analysis.

To identify systematically studies examining corporate publishing, we searched for ad hoc keywords in publication titles, abstracts, and list of keywords of the publication records indexed in the Web of Science (WoS) Core Collection. As reported in Table 1, our bibliometric search strategy builds on keywords such as "corporate publishing" and "publishing firms", but also on combinations of two groups of terms representing the two main concepts of the phenomenon of corporate publishing, i.e. "firm" and "publication". We selected all publication records where one of the firm-related terms and one of the publication-related terms were not separated by more than five words.

The search returned an initial sample of 1,437 records. ${ }^{2}$ We selected articles and reviews in the English language, thus reducing the sample to 913 records. We then examined these publications to identify studies that (i) discussed firms' incentive to publish; (ii) analysed the publication activity of firms or industrial sectors; or (iii) relied on publication data to operationalize and characterize various dimensions of a firm's R\&D activity (e.g. R\&D capabilities, firm-university collaborations). This process led to a sample of 69 studies. We used the refer-

\footnotetext{
${ }^{2}$ We queried WoS using the Boolean operator 'NEAR/5'. Searches where firm-related terms and publicationrelated terms could be separated by more or less than five words (e.g. 'NEAR/3', 'NEAR/4', 'NEAR/6', 'NEAR/7') were of lower recall or precision, respectively. The most recent query was performed on 3 October 2018.
} 
Table 1: Keywords to identify studies on corporate publishing.

\begin{tabular}{|c|c|c|}
\hline \multicolumn{3}{|c|}{ Keywords } \\
\hline \multicolumn{3}{|c|}{$\begin{array}{l}\text { corporate publishing } \\
\text { corporate science } \\
\text { publishing firm* } \\
\text { publishing company } \\
\text { publishing companies }\end{array}$} \\
\hline $\begin{array}{r}\text { firm* } \\
\text { company } \\
\text { companies } \\
\text { corporate* } \\
\text { multinational* } \\
\text { private sector* } \\
\text { R\&D }\end{array}$ & $\begin{array}{l}\text { within } \\
5 \text { terms }\end{array}$ & $\begin{array}{l}\text { publication* } \\
\text { scient* article* } \\
\text { scient* disclosure* } \\
\text { scient* output* } \\
\text { scient* research } \\
\text { academi* article* } \\
\text { academi* output* } \\
\text { academi* research }\end{array}$ \\
\hline
\end{tabular}

ences of these studies to snowball 70 additional studies, thus leading to a total sample of 139 studies. We examined this sample of studies (i) to identify studies that discussed about firms' incentives to publish; (ii) to categorize the research landscape of corporate publishing from the empirical point of view in terms of examined sectors.

\subsection{Why do firms publish?}

We identified studies that discussed one or more incentives for firms to publish by using a thematic coding approach (Miles et al., 1994). We first reviewed each study to extract portions of text, namely 'codes', in which authors discussed incentives for firms to contribute to the production of scientific publications. For examples, we extracted the following codes:

"[...] firms need to demonstrate the merits of their innovations to outside parties, such as regulatory agencies and professional communities, whose assessments influence the commercialization of new products [...]"

(Polidoro and Theeke, 2012, p.1135)

"[...] firms engaged in a patent race can make a credible threat of publishing their research results and thereby force the likely patentee to negotiate a licensing agreement with them prior to receiving the patent [...]"

(Parchomovsky, 2000, p.930)

Of the 139 publications on corporate publishing in our sample, 84 studies (about 60\%) identified or argued about one or more incentives for firms to publish, i.e. it was possible to 
identify at least one thematic code. Codes were then analysed by the research team to crystallize patterns and themes. To do so, each code was elaborated and standardized in sentences such as "to attract high quality scientists", "to stop rival firms from patenting", "to obtain approval and sell products", "to gain credibility towards public funding authorities", "to signal technological capabilities to investors", etc. These were subsequently consolidated into categories of incentives to publish. For examples, the two thematic codes "to gain credibility towards public funding authorities" and "to signal technological capabilities to investors" were grouped into a category called "signalling and reputation building".

The codification process enabled us to identify five categories of incentives for firms to publish. These are: (i) accessing external knowledge and resources (46 studies or $55 \%$ of the sample); (ii) attracting and retaining researchers (36 studies or $43 \%$ of the sample); (iii) signalling and reputation building (44 studies or $52 \%$ of the sample); (iv) supporting IP strategies (32 studies or $38 \%$ of the sample); and (v) supporting commercialization strategies (28 studies or $33 \%$ of the sample). We discuss in the next sections each category of incentive for the complete list of studies by category of incentives).

\subsubsection{Accessing external knowledge and resources}

A considerable number of studies on corporate publishing argued that firms have strong incentives to contribute to scientific publications because publishing enables firms to access complementary and possibly geographically dispersed knowledge and resources. In line with the extensive literature on university-industry collaboration, most of these studies refer to knowledge and resources that are available in the public sector or academic community (e.g. Cockburn and Henderson, 1998; Hicks, 1995; Liebeskind et al., 1996; Okubo and Sjüberg, 2000; Simeth and Cincera, 2016; Stern, 2004; Tijssen, 2009; Zucker et al., 2002).

Publishing, and therefore sharing and disclosing information and knowledge, can be conceived as the 'ticket of admission' firms must purchase to enter the academic network (Rosenberg, 1990). Academic researchers are more inclined to share unpublished information knowledge with researchers that they believe will reciprocate and that are perceived to possess valuable technical knowledge. Publications enable firm researchers to signal that they share academic norms and values as well as to establish their own technical reputation (Hicks, 1995; Okubo and Sjüberg, 2000). High levels of technical reputation may then place firms' researchers in a better 
position to access and build on upstream scientific knowledge (e.g. Hess and Rothaermel, 2011; Zucker et al., 2002).

Co-authorships also provide firm researchers with opportunities to nurture and expand their collaborative networks (Bromfield and Barnard, 2010; Pénin, 2007), while remaining more flexible and less binding than other forms of inter-organizational relationships such as technological alliances (Alexy et al., 2013; Almeida et al., 2011). These interactions contribute to improving a firm's capacity to recognize, absorb, and exploit knowledge that is created elsewhere (e.g. Cockburn and Henderson, 1998; Ding, 2011; Fleming and Sorenson, 2004; Li et al., 2015; Rappa and Debackere, 1992; Simeth and Cincera, 2016; Stern, 2004). Firm researchers are exposed to critical learning opportunities (Liebeskind et al., 1996; Zucker et al., 2002), which can help them to stay at the forefront of a field (Kinney et al., 2004) and to identify emerging technologies (Arora et al., 2018) or commercial applications for their research findings (Friesike et al., 2015). Jong and Slavova (2014) provided evidence that, in the case of the UK therapeutic biotechnology industry, co-authorship collaborations between a firm's researchers and academic researchers exert a positive impact on the number of new drugs the firm is able to push into the development phase (i.e. pre-clinical trials) and on the radicalness of these drugs.

By drawing on publicly funded research, firm researchers also contribute to reducing firms' R\&D costs (Liebeskind et al., 1996; Tijssen, 2004; Tijssen et al., 1996). Publications about a firm's discoveries can generate sufficient interest for academic researchers to conduct collateral research (Hicks, 1995) or to investigate specific problems that the firm itself may lack the resources or knowledge to pursue (Archambault and Larivière, 2011; Liebeskind et al., 1996) or that could be too risky to investigate (Almeida et al., 2011).

\subsubsection{Attracting and retaining researchers}

Research on corporate publishing has argued that publishing could significantly foster a firm's ability to attract and retain researchers (e.g. Arora et al., 2017; Cockburn and Henderson, 1998; Ding, 2011; Gittelman and Kogut, 2003; Hicks, 1995; Li et al., 2015; Liu and Stuart, 2014; Penders and Nelis, 2011). Researchers' human capital represents a critical asset for the firm to perform R\&D and to improve its R\&D capabilities (e.g. Cohen and Levinthal, 1990; Darby et al., 1999; Stephan, 1996). Researchers bring knowledge and capabilities that fuel the firm's R\&D process, but also provide access to social and professional networks that the firm can 
leverage to establish linkages with other research communities (e.g. Cockburn and Henderson, 1998; Liebeskind et al., 1996; Murray, 2004; Okubo and Sjüberg, 2000; Zucker et al., 2002).

Hicks (1995) argued that enabling firm researchers to publish the results of their research is an "intrinsically rewarding" activity: engaging in open science fulfils firm researchers' personal and professional aspirations and helps them to find better jobs. Publishing enables firm researchers to maintain links with the wider academic community (e.g. Fini and Lacetera, 2010; Furukawa and Goto, 2006) and to gain reputation and prestige in this community (e.g. Stern, 2004). The academic community may 'punish' those researchers that do not disclose their knowledge in publications by excluding them from the community itself (McMillan et al., 1995). A firm can also use publications to monitor its researchers' performance in a cost-effective manner. For example, publication outputs can be linked with researchers' promotions or financial rewards (Cockburn and Henderson, 1998; Kinney et al., 2004; Li et al., 2015). Liu and Stuart (2014), focusing on the biopharmaceutical industry, found that laboratory employees who are more prolific in terms of publications receive greater monetary compensations (year-end bonuses) and greater organizational resources.

Publishing also helps a firm to gain a reputation for being a science-minded employer. On the one hand, this facilitates the recruitment and retention of highly regarded researchers (e.g. 'star scientists'), which, in turn, can attract other talented researchers that are eager to work with these researchers (Hess and Rothaermel, 2011; Penders and Nelis, 2011). Disclosures in scientific journals or, more generally, to engage in open science can be conceived as an in-kind compensation for these reputational gains (Lichtman et al., 2000). On the other hand, there is evidence that a firm that shows openness can extract wage discounts. Stern (2004) argued that "scientists pay to be scientists": on the basis of a sample of postdoctoral biologists completing a job search, the study found a firm's science orientation to be negatively related to wages. Similarly, using a survey of science and engineering PhD candidates, Sauermann and Roach (2014) found that firms are likely to pay an additional amount, namely the "price of publishing", when they restrict researchers' possibility of publishing the results of their research - this price of publishing is higher for $\mathrm{PhD}$ candidates who consider themselves to be particularly able from a research perspective or that train in highly ranked institutions. 


\subsubsection{Signalling and reputation building}

Corporate publishing research has argued that publishing enables a firm to build up its reputation and credibility, thus improving the firm's image. The open nature of publications, and their relatively ease of access and diffusion, make this form of research output a powerful instrument for firms to send signals to the outer world. Publications can function as signals for the existence of scientific and technological competences and capabilities, quality of products, scientific findings, or tacit knowledge within the firm (e.g. Arora et al., 2017; Eisenberg, 2000; Hayter and Link, 2018; Hicks, 1995; Nelson, 1990; Okubo and Sjüberg, 2000; Polidoro, 2013).

These signals can reach various receivers. First, a firm's publications can signal to capital markets (e.g. stockholders, perspective investors, venture capitalists) that the firm has important technological competences; that the firm has made an important scientific discovery; or that new products are in the pipeline (e.g. Almeida et al., 2011; Arora et al., 2018; Bergenholtz, 2014; Eisenberg, 2000; Erden et al., 2015; Pénin, 2007). For example, Simeth and Cincera (2016) examined a longitudinal sample of high-tech firms in the US and found evidence of a positive impact of a firm's publication activity and the firm's market value (Tobin's Q). Publishing is also a more cost-effective mechanism than patenting for small firms or start-ups to attract the attention of potential investors (e.g. Almeida et al., 2011; Belenzon and Patacconi, 2014; Hicks, 1995; Kinney et al., 2004). Second, a firm's publications signal technological and scientific proficiency to other industrial researchers and academics. This helps the firm to gain reputation and prestige within the wider scientific community, to diffuse knowledge by disseminating scientific or technical standards (e.g. protocols for clinical trials), to attract potential research partners, and to demonstrate that the firm is close to the development of a new technology (e.g. Almeida et al., 2011; Eisenberg, 2000; Frederiksen, 2004; Mukherjee and Stern, 2009; Muller and Pénin, 2006; Sauermann and Stephan, 2012; Tijssen, 2004). Third, publications enable a firm to gain credibility and reputation to access grants, subsidies, or contracts that are available from public institutions or funding bodies (e.g. Csomós, 2017; Simeth and Raffo, 2013; Stephan, 1996). Finally, the last type of signal is towards suppliers, potential customers, and competitors (e.g. Nelson, 1990; Spencer, 2001). For instance, published outputs may alert suppliers about existing or future products of the firm (Godin, 1996; Nelson, 1990), improve the quality of downstream product/services (Harhoff, 1996), and signal R\&D capabilities to potential partners (Muller and Pénin, 2006). More generally, corporate publishing and other forms of selective revealing could 
stimulate other competitors to reciprocate and to nurture a more open culture in the entire industry (Alexy et al., 2013; Pénin, 2007).

\subsubsection{Supporting IP strategies}

Research has examined corporate publishing as a key component of a firm's strategy to manage and protect its IP portfolio. Publishing enables firms to establish legal property rights for their invention (Godin, 1996; Nelson, 1990). Patent offices issue patents for inventions that represent sufficient advancements over prior art. A firm can strategically disclose pre-patenting information in publications to alter prior art, thus de facto limiting or stopping rivals from patenting the disclosed invention. Such a strategy has been examined by economists and legal scholars in terms of preemptive publication, defensive disclosure, or defensive publishing (e.g. Baker and Mezzetti, 2005; Barrett, 2002; Hayter and Link, 2018; Johnson, 2014; Parchomovsky, 2000; Pénin, 2007). Defensive publishing can help the firm to achieve different strategic objectives.

First, defensive publishing can be an effective IP strategy for both laggards and leaders of a patent race. On the one hand, a laggard can pursue a defensive publishing strategy to extend the patent race (e.g. Baker and Mezzetti, 2005; Bar, 2006; Parchomovsky, 2000). Defensive publications can push the leading rival to invest additional resources in $R \& D$ until sufficient progress is made over prior art, thus increasing the laggard's chances of narrowing the technical gap from the competitor that is ahead in the race. A laggard is more likely to pursue defensive publishing as its chances to leapfrog the leading rival reduce (Lichtman et al., 2000), or as the leading firm gets closer to winning the race (Bar, 2006). Such a strategy can, however, be a double-edged sword for the laggard: defensive publications may provide the leading firm with critical information to accelerate its $\mathrm{R} \& \mathrm{D}$ without necessarily reducing the patentability of the invention (Eisenberg, 2000). ${ }^{3}$

On the other hand, the leader of the patent race can pursue a defensive publishing strategy to lead the laggard to race less vigorously or to push the laggard out of the race (e.g. Baker and Mezzetti, 2005; Lichtman et al., 2000). Although disclosures by the leading firm can provide

\footnotetext{
3 The United States Patent and Trademark Office (USPTO), for example, from 16 March 2013, considers a disclosure "made by the inventor or joint inventor or by another who obtained the subject matter disclosed directly or indirectly from the inventor or a joint inventor" (see 35 United States Code $\S 102$ "Conditions for patentability; novelty") not to constitute prior art if made one year or less before the filing date of the claimed invention. Given that the grace period is currently denied by other major patent offices such as the European Patent Office (EPO) and the Worldwide International Patent Office (WIPO), the laggard's defensive publishing strategy can still block the leading firm from extending the patent protection internationally (Franzoni and Scellato, 2010).
} 
the laggard with key information to reduce the gap, they also reduce the expected value of the patent the laggard aims to race or provide the laggard with critical information to estimate the technical gap from the leading firm, possibly encouraging the laggard to abandon the race. The leading firm is, however, less likely to disclose relevant information when the laggard and the leader can reach a private agreement (Parchomovsky, 2000).

Second, defensive publishing can be conceived as complementary to patenting or trade secrets (Barrett, 2002; Colson, 2001). When a firm holds patents protecting its core inventions, publications around these inventions increase the scope of the associated patents. Publications alter prior art, thus making it more difficult for rivals to patent inventions that are incremental to the firm's core inventions. Publishing therefore enables the firm to stake out IP rights and protect its inventions without incurring the considerable costs associated with 'blanket-patenting' (Rinner, 2003). This patenting-publishing dual strategy is especially effective when the firm's core inventions are less technically challenging, i.e. when it is relatively easy to invent around (Johnson, 2014). It is, however, worth noting that a firm can also strategically combine narrowscope patents with disclosures in publications to increase the licensing revenues (Bar-Gill and Parchomovsky, 2003). With disclosures in publications, the firm gives away secrets and a share of future profits to create incentives for other firms to develop incremental improvements on its original inventions. This, in turn, favours the adoption of the original invention and potential licensing revenues associated with it.

Third, defensive publishing is a cost-effective IP mechanism for a firm to exploit freely the outcomes of its $\mathrm{R} \& \mathrm{D}$ or to operate in a market without the threats that rivals may pose. Defensive publications apply worldwide, while patents are limited to certain jurisdictions - their extension to multiple jurisdictions can be costly for the firm (Colson, 2001). In addition, although the costs of keeping the invention secret are also relatively low, secrecy may still not fully protect the firm from loosing its freedom to commercialize its invention. Reverse engineering, mobility of researchers, and modern business intelligence tools can in fact provide rivals with the opportunity

\footnotetext{
4 The laggard could be in the position of negotiating licensing for the leader's invention even before the leader has granted the patent for that invention, since disclosing relevant information in publications is a credible threat for the leading firms. Parchomovsky (2000), however, argued that such private agreements are unlikely to occur: the patenting firm "will often be unable to ascertain which publication threats are real and which are not" (p. 949). In this regard, the literature on defensive publishing as a strategy to extend or spoil patent races has been the subject to some criticisms. Merges (2004) pointed out that proposed models rely on two main assumptions that are often violated in the real world. It is assumed that a firm pursuing defensive publishing in a patent race (i) has robust information to guess the technical position of the leader in the race; (ii) knows how much to publish about the invention since it can make a relatively reliable prediction about the outcome of the legal test for nonobviousness.
} 
to grant patents to exclude the firm from the market (Pénin, 2007) or to prevent it from profiting from litigation (Johnson, 2014). In both cases, defensive publishing could help firms to benefit from their own innovations in several markets in a relatively less expensive manner compared to other alternatives.

It is worth noting that defensive publishing is not necessarily observed in the form of publications in scientific journals, which is the main focus of this article. A firm can disclose relevant information with presentations at conferences (the proceedings of which are routinely searched by patent examiners) with articles in technical bulletins or using Internet publication services. ${ }^{5}$ Nonetheless, Della Malva and Hussinger (2012) provided evidence that firms' scientific publications in the semiconductor sector challenge the novelty of patent applications at the European Patent Office (EPO) more than other forms of prior art. Although the peer-review process in scientific journals is likely to delay the disclosure of information, it validates the content of defensive publications (Barrett, 2002).

\subsubsection{Supporting commercialization strategies}

The last category of incentives for firms to publish identified by previous studies concerns the ultimate phase of the innovation process, i.e. the commercialization. As in the case of the incentives to publish related to signalling and reputation building, the open nature of publications can signal to prospective customers a firm's new products and/or services. Publications can give publicity to and generate interest about the firm's products or technologies that is sufficient to accelerate the commercialization of these new products or technologies, or even to open new markets for them (e.g. Bergenholtz, 2014; Friesike et al., 2015; Godin, 1996; Nelson, 1990; Pénin, 2007; Simeth and Cincera, 2016). This is especially true in the case of 'sophisticated' or 'professional' customers that could monitor scientific journals to find suitable and specialized products (Arora et al., 2017; Simeth and Raffo, 2013). In this regard, Penders and Nelis (2011) provided evidence of how firms in the food industry use publications to support health claims about their products. In particular, they studied how a leading multinational food company has been able to use a single strategy of credibility engineering - centred around academic peerreviewed publications - to align the knowledge about their products with the scientific consensus

\footnotetext{
${ }^{5}$ Examples of these services include http://www.researchdisclosure.com and http://ip.com/.
} 
and improve credibility of their claims with scientific peers, regulators and consumers (Penders and Nelis, 2011).

In the case of the pharmaceutical and biotechnology sectors, firms use publications to support two critical aspects of the commercialization process of drugs and related products (Sternitzke, 2010). On the one hand, scientific publications could be instrumental in obtaining approval from regulatory agencies. Publications provide scientific evidence that can increase the chances of receiving a positive assessment, hence the final approval of a drug (e.g. Arora et al., 2018; Penders and Nelis, 2011; Pénin, 2007; Simeth and Raffo, 2013). On the other hand, publications could stimulate the diffusion of a drug by advertising its effectiveness and safety to doctors and hospitals (e.g. Azoulay, 2002; Hicks, 1995; Polidoro and Theeke, 2012; Rafols et al., 2014; Sismondo, 2012). This strategy is particularly effective when a firm contributes to articles in top-tier journals: doctors and other decision makers are likely to consider the firm's knowledge disclosures and claims in such journals to be more reliable than the information included in the firm's marketing and promotional material:

"For a drug company, a favourable trial is worth thousands of pages of advertising, which is why a company will sometimes spend upwards of a million dollars on reprints of the trial for worldwide distribution. The doctors receiving the reprints may not read them, but they will be impressed by the name of the journal from which they come. The quality of the journal will bless the quality of the drug" (Smith et al., 2005, p.364)

The use of publications in support the of approval and commercialization of pharmaceutical products are closely interrelated. Sternitzke (2010) provided evidence that publishing is part of the so-called "drug lifecycle": by examining a sample of new molecular entities approved by the Food and Drug Administration (FDA) between 1999 and 2004, the author found that, on average, each drug in the sample was accompanied by about 19 publications and 23 patents, and that pharmaceutical firms developed strategies combining both patents and publications to obtain drug approval, stimulate commercialization, and influence the adoption rate of the drug.

\subsection{How does firms' engagement in publishing differ across sectors?}

The framework of firms' incentives to publish we presented in the previous section provides theoretical insights into what may lead firms to contribute to scientific publications. However, 
from the empirical point of view, extant literature has not systematically investigated the extent to which firms' engagement in publication activity may differ across industrial sectors.

Of the 139 studies on corporate publishing we identified, 105 studies (76\%) are empirical, while 34 studies (24\%) are conceptual or develop models - see Table 2 (panel A). More than half of the empirical studies (59\%) examined corporate publishing at the level of the firm, while the remaining studies focused on collaborations (15\%), researchers $(11 \%)$, patents $(6 \%)$, or other units of analysis (9\%). When firm-level empirical studies are distinguished by number of sectors and countries considered, we can observe that a very limited number of studies examined corporate publishing on the basis of firm samples covering multiple sectors and countries.

As summarized in Table 2 (panel B), 41 firm-level empirical studies (66\%) relied on a sample of firms drawn from a single sector. A considerable proportion of these studies (78\%) examined the publication activity of firms that operate in sectors where scientific knowledge is a critical input for the R\&D process. These include the pharmaceutical, biotechnology, and chemical sectors. The sample of firm-level empirical studies also includes 46 studies that are singlecountry $(74 \%)$. These studies are mostly focused on samples of firms located in the United States, Japan, or the United Kingdom. More than half of firm-level empirical studies, i.e. 32 studies (52\%), are both single-sector and single-country, while 14 studies (23\%) are multi-sector, but single-country, and 9 studies (15\%) are multi-country, but single-sector.

Of the sample of firm-level empirical studies, only seven studies (11\%) investigated the phenomenon of corporate publishing on the basis of multi-sector and multi-country firm samples. It is, however, worth noting that four of these studies (Godin, 1996; Hicks et al., 1996; Lim, 2004; Tijssen, 2004) considered firms from no more than three sectors and/or focused on samples including a relatively low number of observations (i.e. samples of fewer than 200 firms). As a result, extant literature provides us with limited understanding of the extent to which corporate publishing features in relatively under-examined sectors. Only three studies relied on relatively large multi-sector and multi-country samples of firms (Belenzon and Patacconi, 2014; Csomós, 2017; Csomós and Tóth, 2016). We build on these efforts by conducting an analysis of the publication activity of a global sample of 2,500 firms classified into 20 industrial sectors. 
Table 2: Studies on corporate publishing: types, units of analysis, sectors, and countries.

A: Types and units of analysis

\begin{tabular}{llc}
\hline Study type & Unit of analysis & Studies \\
\hline \multirow{2}{*}{ Empirical } & Firm & 62 \\
& Collaboration & 16 \\
& Researcher & 12 \\
& Patent & 6 \\
Conceptual/modeling & Other & 9 \\
All studies & - & 34 \\
\hline Source: Authors' elaboration. & 139 \\
\end{tabular}

Source: Authors' elaboration.

B: Firm-level empirical studies: sectors and countries

\begin{tabular}{llccc}
\hline & \multicolumn{4}{c}{ Country } \\
& & Single & Multi & All studies \\
\hline \multirow{2}{*}{ Sector } & Single & 32 & 9 & 41 \\
& Multi & 14 & 7 & 21 \\
& & & & \\
& All studies & 46 & 16 & 62 \\
\hline \multicolumn{2}{l}{ Source: Authors' elaboration. }
\end{tabular}

\section{Data and methodology}

We present below the firm sample, the methodology and the data collection process we relied on to perform an empirical analysis aimed at examining systematically how does firms' engagement in publishing differs across sectors.

\subsection{Firm sample}

We examine the publication activity of the 2,500 firms worldwide that were most active in terms of R\&D investment in 2013. These firms were drawn from the 2014 EU Industrial R\&D Investment Scoreboard (henceforth, the Scoreboard), a rank of the most active firms in terms of $\mathrm{R} \& \mathrm{D}$ that is published by the Joint Research Centre of the European Commission on a yearly basis since 2004 .

We focused the analysis on these firms for several reasons. First, although the firm sample does not include relatively less R\&D-active firms, $90 \%$ of global private R\&D investment in 2013 can be attributed to firms included in the Scoreboard. ${ }^{6}$ Second, we could access the complete

\footnotetext{
${ }^{6}$ See page 17 of the 2014 Scoreboard, http://iri.jrc.ec.europa.eu/scoreboard14.html; it is worth noting that R\&D data used to produced the Scoreboard consider R\&D investment "[...] as the cash investment funded by the companies themselves. It excludes REDD undertaken under contract for customers such as governments
} 
list of subsidiaries owned by these firms. These data, which were provided by Bureau van Dijk's ORBIS to the Joint Research Centre of the European Commission, included names and geographical location of 569,919 subsidiaries owned by firms included in the Scoreboard. Finally, the firm sample provides a relatively comprehensive coverage of sectors. Firms are classified into 40 sectors according to the Industry Classification Benchmark (ICB) at 3-digit level. For the purpose of the analysis, we aggregated sectors with a relatively low number of firms into 'macro' sectors of at least 25 firms/observations. This led to 20 'aggregated' sectors that are described in terms of number of firms and associated subsidiaries in Table 3 for more details about the aggregation process).

Table 3: Sample firms and subsidiaries by industrial sector.

\begin{tabular}{lcc}
\hline Sector & Firms & Subsidiaries \\
\hline Aerospace \& Defence & 51 & 11,699 \\
Automobiles \& Parts & 148 & 37,384 \\
Basic Resources & 65 & 15,983 \\
Chemicals & 139 & 30,130 \\
Construction \& Materials & 72 & 43,911 \\
Consumer Services & 64 & 39,375 \\
Electronic \& Electrical Equipment & 242 & 33,663 \\
Financials & 56 & 48,911 \\
Food \& Beverage & 69 & 20,631 \\
Health Care Equipment \& Services & 97 & 15,407 \\
Industrial Engineering & 212 & 38,939 \\
Oil \& Gas, Alternative Energy & 51 & 31,806 \\
Other Industrials & 106 & 46,295 \\
Personal \& Household Goods & 129 & 26,384 \\
Pharmaceuticals \& Biotechnology & 294 & 17,691 \\
Software \& Computer Services & 268 & 19,197 \\
Support Services & 32 & 55,49 \\
Technology Hardware \& Equipment & 334 & 23,553 \\
Telecommunications & 29 & 23,592 \\
Utilities & 42 & 39,819 \\
& & \\
All sectors & 2,500 & 569,919 \\
\hline
\end{tabular}

Source: Authors' elaboration.

or other companies. It also excludes the companies' share of any associated company or joint venture RED investment. Data is based on what is disclosed in the annual report and accounts, and is therefore subject to the accounting definitions of RED. For example, a definition is set out in International Accounting Standard (IAS) 38 'Intangible asset' and is based on the OECD 'Frascati' manual. Research is defined as original and planned investigation undertaken with the prospect of gaining new scientific or technical knowledge and understanding. Expenditure on research is recognised as an expense when it is incurred. Development is the application of research findings or other knowledge to a plan or design for the production of new or substantially improved materials, devices, products, processes, systems or services before the start of commercial production or use. Development costs are capitalised when they meet certain criteria and when it can be demonstrated that the asset will generate probable future economic benefits. Where part or all of R\&D costs have been capitalised, the additions to the appropriate intangible assets are included to calculate the cash investment and any amortisation eliminated" (page 87 of the 2014 Scoreboard). 


\subsection{Publication data collection}

To identify publications authored by researchers based at the firms and subsidiaries in our sample, we matched firm and subsidiary names with organization names reported in authors' affiliation addresses in publications. Given the lack of standardized organization names in publication data, this matching was particularly challenging. Our empirical strategy involved a number of steps which are described below-more details about the methodological approach are reported elsewhere, see Rotolo and Camerani (2017). We first harmonized and cleaned firm and subsidiary names to ensure that the recall of our queries was not affected by incomplete or misspelled organization names. ${ }^{7}$ To do so, we first identified acronyms and variations of parent firm names. For example, "Dutch State Mines", "Koninklijke DSM", "Royal DSM" and "DSM" were found as name variations for the parent firm "Koninklijke DSM NV". A desktop search enabled us to identify 1,384 name variations for 1,084 parent firms (about $43 \%$ of the sample).

We then excluded all subsidiaries whose names included their parent firm names (including acronyms and variations). Publications co-authored by researchers employed at these subsidiaries (e.g. "Continental Tires Canada") are automatically retrieved when searching for their parent firms' publications (e.g. "Continental"). Symbols, punctuation marks, double spaces, business entity abbreviations (e.g. "Ltd", "Inc", "GmbH"), and country names (e.g. "Abbvie Spain" was revised as "Abbvie") were also removed from subsidiary names by using regular expressions. All the cases of subsidiary names where our regular expressions were too aggressive (e.g. "SCA" is a subsidiary name, "Svenska Cellulosa Aktiebolaget", but also a French business entity abbreviation, "Société en Commandite par Actions") were manually revised. ${ }^{8}$

We then built a query for each parent firm. Each query included a parent firm's name and its variations, and associated subsidiary names. We searched for these organization names in the

\footnotetext{
7 We defined recall as the ratio between true positives (i.e. the number of publications that are authored by researchers employed at a given firm or subsidiary) and the sum of true positives and false negatives (i.e. the number of publications that are authored by researchers employed at a given firm or subsidiary that are not captured by our query).

8 This cleaning process enabled us to "flag' subsidiaries with common names (e.g. "plant" or "computer systems"), so to facilitate the subsequent cleaning of false positive publication records-i.e. publication records that are identified by a query as publications that are authored by researchers employed at a given firm or subsidiary even though these do not involve researchers of the firm or subsidiaries in the list of authors.
} 
"AD" field (authors' affiliation address) ${ }^{9}$ of the WoS Core Collection, ${ }^{10}$ limiting our search to the 2011-2015 period. Given that most of the parent firms in our sample are multinationals, we searched for parent firm names with no country constraints. Subsidiaries were instead searched in authors' affiliation addresses together with the information about the countries in which these were located.

Queries returned an initial sample of more than 1.2 million publication-firm observations. Given that our queries aimed at maximizing recall, this initial sample included a considerable number of false positive publication records. To remove these, we first used regular expressions to exclude publication records involving only authors from academic institutions (e.g. universities, hospitals, schools) or records that our queries captured because subsidiary names were equal to the names of cities as reported in authors' affiliation addresses. We then manually checked, with the support of research assistance, all the remaining publication records. ${ }^{11}$ This process led to a final sample of 342,152 publication-firm observations or 314,411 unique publication records from 2011 to 2015. In the next section, we analyse these data to characterize the corporate publishing across our 20 industrial sectors.

\section{Results}

\subsection{Do firms publish?}

The number of publications our firms contributed to during the observation period is 314,411 (our dataset includes 342,152 publication-firm observations). The magnitude of this activity is comparable with the total academic publication output of a country such as France in the same period (about 357,000 publications). ${ }^{12}$ About $84 \%$ of our firms (i.e. 2,088 firms) are 'publishing firms', i.e. they contributed to at least one publication. The percentage of publishing firms

\footnotetext{
9 We also tested our queries on the "Organization" ("OO") and "Organization-Enhanced" ("OG") fields in WoS. These fields include organization names as extracted from authors' affiliation addresses. An exploratory analysis based on a sample of parent firms, however, provided evidence that the "OO" and "OG" fields were characterized by a lower recall as compared to using the "AD" field.

${ }^{10}$ It is worth noting that firms may also publish in professional journals for which Scopus is likely to provide a more comprehensive coverage than WoS. However, our aim was to capture firms' involvement in the production of scientific publications. In this regard, WoS data have been extensively used by studies examining corporate publishing (e.g. Arora et al., 2018; Cassiman et al., 2008; Chai and Shih, 2016; Polidoro, 2013).

${ }^{11}$ Regular expressions enabled us to exclude 681,896 false positive publication-firm records, i.e. about $54 \%$ of the initial sample of $1,273,481$ publication-firm records. The remaining sample was manually checked by a team of research assistants, who identified an additional set of 248,723 false positive publication-firm records, i.e. about $20 \%$ of the initial sample publication-firm records.

${ }^{12}$ The number of publications involving French academic institutions was identified using the following query in WoS: $(\mathrm{AD}=($ "CHU" SAME "France") $\mathrm{OR} \mathrm{AD}=$ ("Ecole" SAME "France") $\mathrm{OR} \mathrm{AD}=$ ("Interuniv" SAME
} 
is above $90 \%$ for seven industrial sectors. These are: Oil \& Gas, Alternative Energy (100\%), Utilities (100\%), Pharmaceuticals \& Biotechnology (98.6\%), Health Care Equipment \& Services (96.9\%), Chemicals (96.4\%), Aerospace \& Defence (96.1\%), and Food \& Beverage (92.8\%). The sector with the lowest percentage of publishing firms (58.6\%) is Software \& Computer Services. Conference or workshop proceedings and software developments tend to be more prominent research outputs than scientific publications in this sector (e.g. Boyack et al., 2005).

The distribution of the number of publications by publishing firms is highly skewed: about $7.2 \%$ of the publishing firms in the sample contributed to one publication, while the top $1 \%$ publishing firms contributed to about one-third of the publications in our sample. The median value of this distribution is 26 publications. ${ }^{13}$ The top three most active firms are two large pharmaceutical firms (Roche Holding AG and Pfizer Inc with 9,948 and 9,810 publications, respectively) and one large firm in Software \& Computer Services (International Business Machines Corp, namely IBM, with 8,131 publications).

Figure 1 (left) shows the distribution of the number of publications per publishing firm by sector together with the percentage of publishing firms in each sector. The sector with the highest median value of publications per firm is Oil \& Gas, Alternative Energy (81), followed by Utilities (61), Food \& Beverage (56), Pharmaceuticals \& Biotechnology (55), and Aerospace \& Defence (53). When the number of publications a firm contributed to from 2011 to 2015 is normalized by the firm's total R\&D investment in the same period - we refer to this indicator as publication intensity - Utilities, Basic Resources, and Pharmaceuticals \& Biotechnology, Food \& Beverage, and Oil \& Gas, Alternative Energy are the sectors with the highest median values, i.e. $0.25,0.24,0.20,0.20$, and 0.19 publications per $€$ million invested in $\mathrm{R} \& \mathrm{D}$, respectively. This analysis is depicted in Figure 1 (right). Although the ranks of sectors by median values of the number publications and publication intensity present some differences, these differences are not statistically significant (Spearman's rank correlation: $\rho=0.93, p<0.001$ ).

\subsection{Is corporate publishing declining or increasing?}

There is not unanimity on whether corporate publishing is a growing or declining phenomenon, as previous studies found mixed results. On the one hand, research has provided evidence of

\footnotetext{
"France") $\mathrm{OR} \mathrm{AD}=($ "Polytech" SAME "France") $\mathrm{OR} \mathrm{AD}=$ ("Sch" SAME "France") $\mathrm{OR} \mathrm{AD}=$ ("Univ" SAME "France")) AND PY=(2011 OR 2012 OR 2013 OR 2014 OR 2015).

${ }^{13}$ Publishing firms contributed, on average, to 164 publications; when non-publishing firms are also taken into account, the average reduces to 137 .
} 


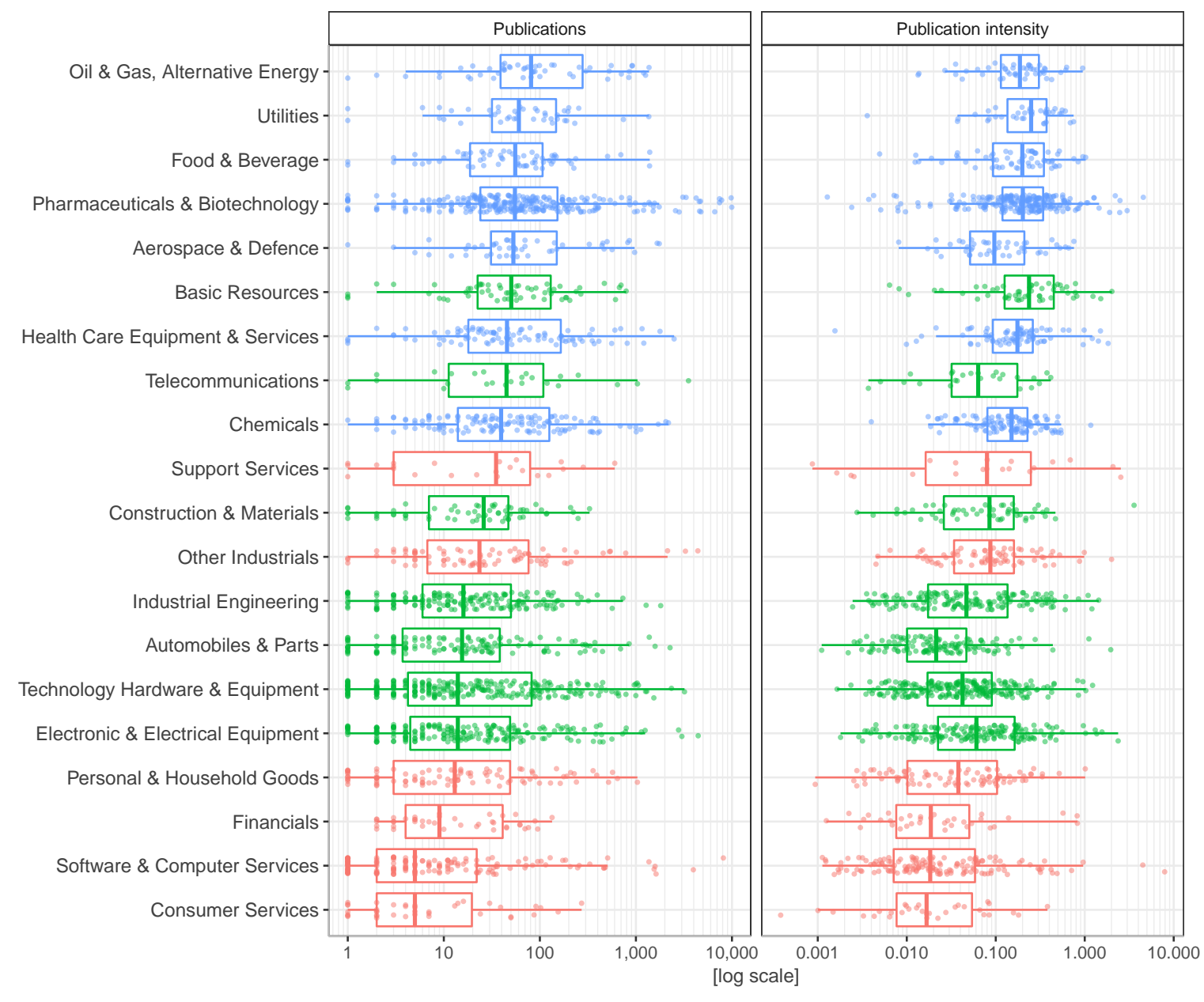

Percentage of publishing firms (50\%;80\%] (80\%;90\%]

Figure 1: Box-plot of the number of publications per publishing firm (left), i.e. firms that contributed to at least one publication from 2011 to 2015, and number of publications per publishing firm by R\&D investment, namely publication intensity (right). Vertical lines inside the boxes represent median values, boxes the interquartile range (IQR), and horizontal whiskers extend \pm 1.5 IQR outside the box. Circles represent publishing firms: the box-plot on number of publications per publishing firm (left) includes 2,088 firms, while the box-plot on publication intensity (right) includes 1,851 publishing firms for which R\&D investment data were available from 2011 to 2015. Sectors are ordered by the median value of the number of publications per publishing firm. Colours represents the proportion of publishing firms in a sector.

Source: Authors' elaboration.

a growing number of publications involving firm researchers (e.g. Archambault and Larivière, 2011; Godin, 1996; Halperin and Chakrabarti, 1987). On the other hand, research has also provided evidence that corporate publishing is a declining phenomenon (e.g. Arora et al., 2018; Larivière et al., 2018; Olmeda-Gómez et al., 2015; Rafols et al., 2014; Tijssen, 2004). At the same time, other studies found a decrease followed by an increase in corporate publishing or vice versa (e.g. Hicks et al., 1996; Narin and Rozek, 1988; Sun et al., 2007). 
However, finding a general trend by comparing the growth/decline figures of different studies is a quite difficult task, given the different geographical, sectoral and temporal focus of these works, and the different methodologies used to collect publication data.

Our data suggest that the number of publications involving firms in our sample grew by $9.4 \%$ from 2011 to 2015 , corresponding to a yearly growth rate of $2.3 \% .{ }^{14}$ We made some robustness checks to account for the extent to which this trend may be a result of the continuous expansion of the coverage of WoS. When the analysis is restricted to the subset of journals that were indexed in WoS both in 2011 and 2015, we observed similar growth rates (8.0\% from 2011 to 2015 and of $1.9 \%$ on a yearly basis). In addition, there is evidence of growth (6.9\% from 2011 to 2015 and $1.7 \%$ on a yearly basis) even when the analysis is restricted to the subset of journals in which firms in our sample published in 2011 or 2015.

The magnitude of the phenomenon of corporate publishing has therefore grown in absolute terms. However, the number of publications co-authored by our firms out of the whole set of records indexed in WoS has declined from $2.6 \%$ in 2011 to $2.3 \%$ in 2015. The number of records in WoS has grown by about 5.6\% from 2011 to 2015 on a yearly basis, while we observed a growth of $2.3 \%$ for our sample of firms.

At the level of the sector, we observed both growing and declining trends in corporate publishing (see Table 4). For some sectors, the number of publications involving our firms grew by more than $5 \%$ on a yearly basis. These include Construction \& Materials $(10.9 \%)$, Consumer Services (10.9\%), Oil \& Gas, Alternative Energy (8.4\%), Financials (8.3\%), Industrial Engineering (6.4\%), and Automobiles \& Parts (5.5\%). For a few sectors, we instead observed a decline of less than $2 \%$ on a yearly basis. These include Chemicals $(-1.2 \%)$, Support Services $(-1.2 \%)$, Personal \& Household Goods $(-1.4 \%)$, and Food \& Beverage $(-1.7 \%)$. It is worth noting that those sectors characterized by the highest growth rates are among the sectors characterized by the lowest publication intensity (see Figure 1), thus suggesting the presence of some sort of 'catching up process' for these sectors.

\footnotetext{
${ }^{14}$ Firms with their headquarters located in the US represent the largest proportion of publishing firms (i.e. about $32 \%$ or 670 out of 2088 publishing firms). The involvement of these firms in the production of scientific publications also grew by $6.0 \%$ from 2011 to 2015 and $1.5 \%$ on a yearly basis.
} 


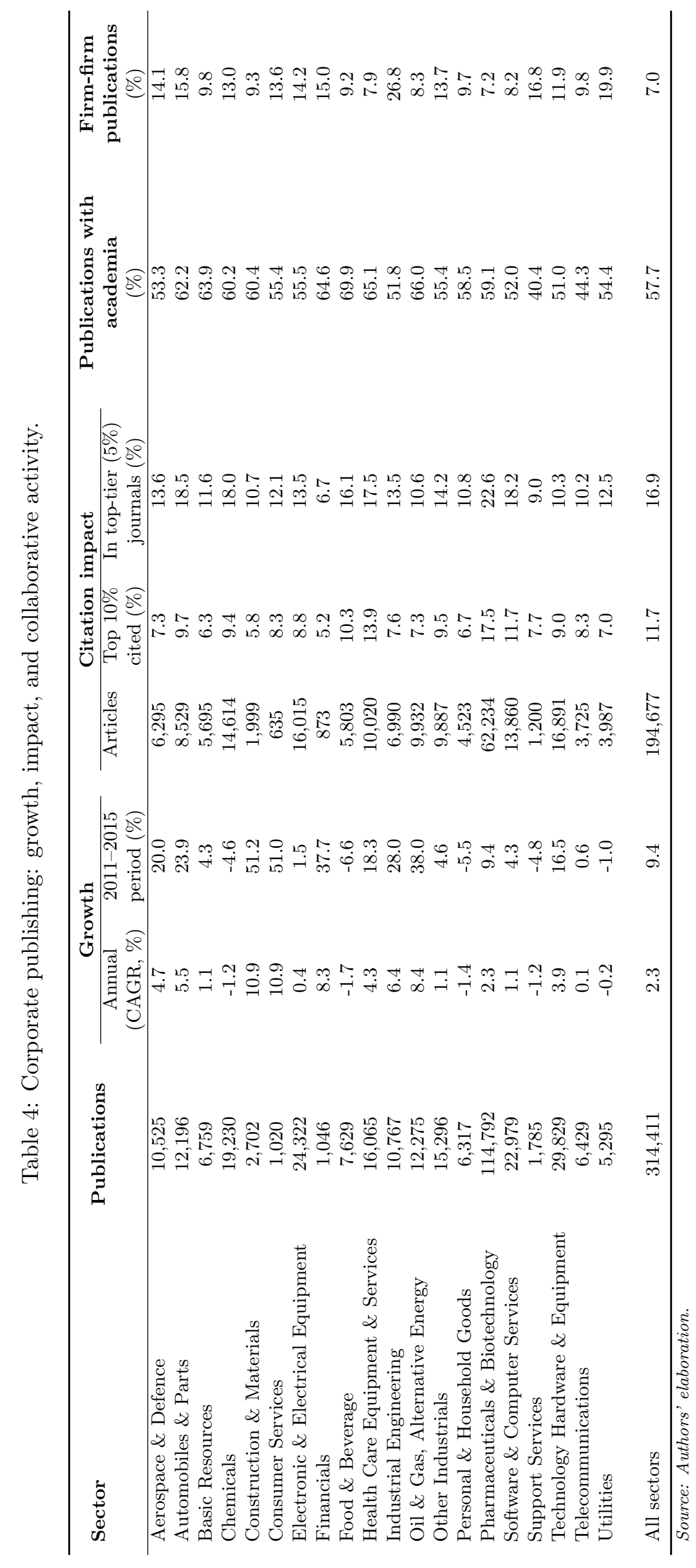




\subsection{Do firms contribute to highly cited publications?}

We examined the extent to which firms contributed to scientific publications that are highly cited by subsequent research. We focused on article document type ${ }^{15}$ and considered an article to be 'highly cited' if the article is within the top $10 \%$ most cited articles in the corresponding research areas (proxied with WoS subject areas) and year of publication. ${ }^{16}$ Such a strategy enabled us to account for cross-field, cross-time-period, and cross-document type differences (Leydesdorff and Opthof, 2011; Schubert and Braun, 1986).

The percentage of articles co-authored by our firms that are in the top $10 \%$ most cited articles is higher than expected, i.e. about $12 \%$. This finding seems to suggest the presence of two main mechanisms: on the one hand, firms may be more selective in what to publish when compared to other organizations (Hicks, 1995); on the other hand, in line with the argument about the signalling effects that publications may generate, firms may be choosing collaborators that may lead to publications that can reach the scientific audience to a greater extent. Apart from these two mechanisms, other factors can be playing a role in explaining the citation pattern observed. For example, some research projects can be hard or too expensive to replicate, making the articles coming out of them the only possible reference for future studies in similar or related fields (this can be the case for Pharmaceuticals \& Biotechnology). There is, however considerable heterogeneity among industrial sectors. Four sectors are characterized by a proportion of highly cited articles of $10 \%$ or more (see Table 4). These are: Pharmaceuticals \& Biotechnology (17.5\%), Health Care Equipment \& Services (13.9\%), Software \& Computer Services (11.7\%), and Food \& Beverage (10.3\%). The proportion of top $10 \%$ most cited articles is the lowest in the case of Financials (5.2\%), Construction \& Materials (5.8\%), Basic Resources (6.3\%), Personal \& Household Goods (6.7\%), and Utilities (7.0\%).

\footnotetext{
${ }^{15}$ Articles represent the greatest proportion of document type to which our firms contributed (62\% or 194,677 records). According to the WoS classification, the remaining publication records are biographical item, book, book chapter, editorial material, letter, meeting abstracts, proceedings paper, and review.

${ }^{16}$ The use of WoS subject areas for citation normalization has been subject of much debate in the scientometrics and research evaluation communities. Major concerns have been around indexers' subjectivity and a lack of coherence in the aggregation of journals (e.g. Pudovkin and Garfield, 2002; van Eck et al., 2013; Wang and Waltman, 2016). It is, however, worth noting that research has also argued that alternative clustering approaches, such as those based on the clustering of citation data (e.g. Waltman, Ludo; Van Eck, 2012), present considerable validation challenges: fields are proxied with algorithmically generated clusters that are difficult to name or interpret (Leydesdorff and Bornmann, 2016). Rafols and Leydesdorff (2009) suggested that the use of WoS subject areas for normalization purposes can be particularly problematic in the case of detailed evaluation where the 'indexer effect' may considerably affect the results, but the WoS classification is expected to perform relatively well producing - in the case of large numbers of publications - results that are meaningful.
} 
We compared these patterns with those observed using an indicator based on WoS journal Impact Factors. As previous research argued (e.g. Hicks et al., 2015), the Impact Factor indicator is not appropriate for assessing the research impact at the level of the single research outcome. For this reason, we use this indicator for a coarse comparison. For each article in our sample, we assessed whether the article was published in a top-tier journal, i.e. a journal that is within the top $5 \%$ journals by Impact Factor in at least one of the WoS subject areas to which the journal is assigned in a given year of observation. ${ }^{17}$ This analysis provided evidence of patterns similar to those observed using the top $10 \%$ most cited indicator (Spearman's rank correlation: $\rho=0.74, p<0.001)$. About $17 \%$ of the articles involving our firms are published in journals that can be considered as top-tier in the corresponding research areas. This percentage is the highest (see Table 4) in the case of Pharmaceuticals \& Biotechnology (22.6\%), Automobiles \& Parts (18.5\%), Software \& Computer Services (18.2\%), Chemicals (18.0\%), and Health Care Equipment \& Services (17.5\%).

\subsection{Are firms involved in collaborative publications?}

In line with general trends observed in science (e.g. de Solla Price, 1963; Fanelli and Larivière, 2016; Parish et al., 2018; Wuchty et al., 2007), publications involving firm researchers are often co-authored by two or more authors. Of the unique 314,411 publications to which our firms contributed, only $5.6 \%$ are authored by single researchers, and these researchers are based at one of our firms. Our framework identified accessing external knowledge and resources as one of the key category of incentives for firms to contribute to the production of scientific publications. Publishing represents an 'admission ticket' to access the academic network (Rosenberg, 1990). This assertion finds support in our data, since about $58 \%$ of the publications involving our firms also involve at least one academic institution. ${ }^{18}$

Firms' propensity to publish with academic institutions varies considerably with the sectors in which firms operates (see Table 4). For example, as reported in Table 4, the proportion of firms' publications involving academic institutions is the highest in the case of Food \& Beverage (69.9\%), Oil \& Gas, Alternative Energy (66.0\%), Health Care Equipment \& Services (65.1\%),

\footnotetext{
${ }^{17}$ At the time of this research (October 2017), we identified 1,475 journals out of 12,040 journals listed in the WoS Journal Citation Report to be top-tier in at least one subject area.

${ }^{18}$ We identified publications involving at least one academic institutions using regular expressions. More precisely, we tagged all publication records that included one or more of the following WoS organization abbreviations in the list of affiliation addresses: CHU, Ecole, Interuniv, Politecn, Polytech, Sch, Scuola, Univ, Universytet, and Universytetu.
} 
Financials (64.6\%), and Basic Resources (63.9\%); while it is the lowest in the case of Software \& Computer Services (52.0\%), Industrial Engineering (51.8\%), Technology Hardware \& Equipment (51.0\%), Telecommunications (44.3\%), and Support Services (40.4\%).

Firms' publications are also characterized by a certain level of collaboration activity between firms. About 7.0\% of the publications involves two or more firms in our sample. Firms' propensity to publish only with other firms in our sample is the highest in the case of Industrial Engineering (26.8\%), Utilities (19.9\%), Support Services (16.8\%), Automobiles \& Parts (15.8\%), and Financials (15.0\%).

\section{Discussion}

The contribution of our paper is twofold. First, on the basis of a global sample of firms that operate in 20 industrial sectors, we provided systematic evidence that corporate publishing is a phenomenon of a considerable magnitude. Firms do publish and this phenomenon is not limited to the more science-oriented sectors such as pharmaceuticals, biotechnology, and chemicals. Most of the world's significant spenders on R\&D also publish scientific articles: $84 \%$ of the firms contributed to at least one publication, with a median value of 26 publications per publishing firm over an observation period of five years (2011-2015). Also, our analysis revealed that the contribution of firms to science has grown in terms of number of publications $(2.3 \%$ on a yearly basis). It is, however, worth noting that this growth has been slower than the growth observed in the total production of scientific publications as detected in WoS (5.6\% on a yearly basis). Also, our analysis suggested that firms contributed to highly cited articles more than expected (about $12 \%$ of firm's articles are within the top $10 \%$ most cited articles) and that firm researchers often collaborate with researchers working in academic institutions (about $58 \%$ firms' publications involves academic researchers).

Second, our paper represents the first attempt to systematize the literature on firms' incentives to publish. Building on research in science policy and innovation studies, economics, and management, we developed a framework of five categories of incentives, some of which found empirical support on our data. For example, we argued that publishing enables firms to access external knowledge and resources, to attract and retain researchers, to signal their capabilities and to build a reputation, and to support IP and commercialization strategies. These incentives contribute to explaining the magnitude and the features of corporate publishing that our 
empirical analysis identified. Furthermore, the high proportion of firms' publications involving academic institutions provides some support to the argument that publishing opens 'channels' that firms can use to access knowledge and resources that are available beyond their organizational boundaries. Co-authorship ties can help firm researchers to establish collaborative linkages with external researchers, thus to expand the network from which they can potentially draw knowledge and resources (Hicks, 1995; Pénin, 2007). Also, the relatively high proportion of highly cited firms' publications seems to support the use of publications to attract and retain talents (e.g. Sauermann and Roach, 2014; Stern, 2004) as well as to signal to investors and stakeholders firms' research quality and innovation capabilities (e.g. Arora et al., 2018; Simeth and Cincera, 2016).

It is worth noting that the firms' incentives to publish we identified are closely related to the R\&D process. For this reason, we further explored this issue by comparing sectors' propensity to publish with the magnitude of their R\&D efforts. To do so, we first calculated a firm's R\&D intensity - i.e the firm's R\&D investment in a given period divided by the firm's net sales in the same period - and compared this with the measure of publication intensity we defined in Section 4.1 - i.e. the firm's number of publications in a given period divided by the R\&D expenditures in the same period. ${ }^{19}$ We then distinguished between four types of sectors on the basis of the proportion of firms with R\&D intensity and publication intensity above or below the corresponding median values of the sample. ${ }^{20}$

As depicted in Figure 2, Quadrant I includes sectors that are characterized by relatively high levels of R\&D intensity and publication intensity since more than $50 \%$ of the firms in these sectors feature values of $R \& D$ intensity and publication intensity above the corresponding median values. Pharmaceuticals \& Biotechnology, Health Care Equipment \& Services, and Aerospace \& Defence are included in this quadrant. Sectors that are characterized by relatively low levels of R\&D intensity and high levels of publication intensity populate Quadrant II. These are Utilities, Oil \& Gas, Alternative Energy, Basic Resources, Food \& Beverage, Chemicals, Construction \& Materials, Other Industrials. Quadrant III includes sectors which are characterized by relatively low levels of both R\&D intensity and publication intensity. Sectors such as Financials, Consumer

\footnotetext{
${ }^{19}$ By using a measure of publications intensity, as opposed to a simple publication count, we classify sectors on the basis of the average number of publications per unit of $R \& D$ expenditure. This enables us to account for the relative cost for producing a scientific publication by sector.

${ }^{20}$ The analysis relies on 1,938 firm-sector observations from 2011 to 2015 . R\&D investment and/or net sales data are missing for 565 firm-sector observations.
} 


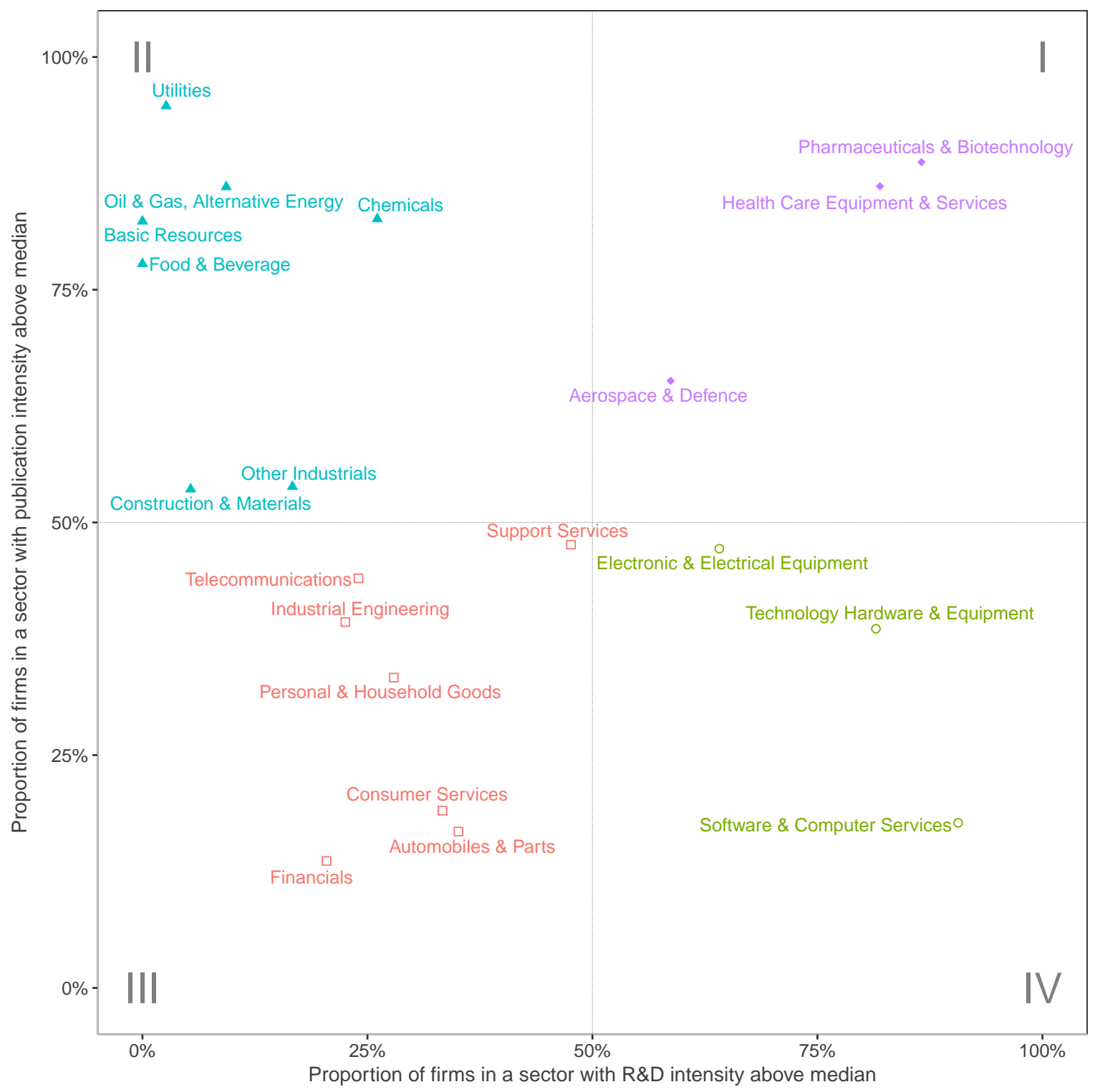

Figure 2: Classification of sectors based on R\&D intensity (i.e. total R\&D investment in the 2011-2015 period out of total net sales in the same period) and publication intensity (i.e. number of publications in the 2011-2015 period out of total R\&D investment in the same period). The horizontal axis represents the proportion of firms in a sector with R\&D intensity above the sample median; while the vertical axis represents the proportion of firms in a sector with publication intensity above the sample median. The colours represent groups of sectors above/below the $50 \%$ threshold of the two axes.

Source: Authors' elaboration.

Services, and Automobiles \& Parts belong to this quadrant. Finally, Quadrant IV identifies sectors that present relatively high levels of R\&D intensity and low levels of publication intensity, i.e. Electronic \& Electrical Equipment, Technology Hardware \& Equipment, and Software \& Computer Services. 
The sector taxonomy presented in Figure 2 suggests that the strength of firms' incentives to publish is likely to differ across sectors. Quadrant I and Quadrant III include sectors where one observes levels of firms' involvement in the production of scientific publications that are to a certain extent corresponding to firms' R\&D efforts. This seems to describe a 'paradigm' that underlies most of the conceptual and empirical literature on corporate publishing, i.e. the more a firm is engaged in $R \& D$ activities, the more the firm will experience incentives to publish, and hence engage in the production of scientific publications. A clear example of this is the considerable research efforts made to examine the Pharmaceutical \& Biotechnology sector (e.g. Azoulay, 2002; Ding, 2011; Gittelman and Kogut, 2003; Polidoro and Theeke, 2012; Rafols et al., 2014).

However, sectors in Quadrant II and Quadrant IV represent a divergence from this 'paradigm'. These are areas that have been subject of very little research by the literature on corporate publishing. In Quadrant II, firms' publication intensity is similar to the publication intensity observed for firms operating in sectors in Quadrant I, although their level of R\&D intensity is much lower. This disproportionally high level of firms' publication intensity suggests that firms' incentives to publish could be particularly strong in sectors populating Quadrant II. For example, assuming the proportion of publications with academic researchers as an indicator of the extent to which publishing is an incentive for firms to access external knowledge and resources, we observe the highest proportion of academic publications (above 60\%) in the case of three sectors in Quadrant II.

Conversely, in Quadrant IV, we observe disproportionally low levels of firms' publication intensity, thus suggesting that firms' incentives to publish are relatively weaker when compared to other sectors with similar levels of R\&D intensity. Other forms of research outputs may be more prominent in Quadrant IV sectors. For example, in Software \& Computer Services, conference or workshop proceedings and software developments are recognized to be more relevant than scientific publications (e.g. Boyack et al., 2005). Also, while in Pharmaceuticals \& Biotechnology and Health Care Equipment \& Services scientific publications are crucial inputs to seek approval for the commercialization of drugs and medical devices, their role may be less prominent for the commercialization of products in Electronic \& Electrical Equipment and Technology Hardware \& Equipment.

Overall, this suggests that corporate publishing is not limited to a few 'usual suspects' sectors, but it is a feature of most sectors. However, the literature on corporate publishing has 
mostly focused on more science-oriented sectors. These have received disproportionate attention compared to other sectors, which diverge from the paradigm that has been put forward by the extant literature. Our results demonstrated that limiting the analysis to science-oriented sectors significantly limits our understanding of corporate publishing, and that more research is needed to shed some light on the publication activity and the strengths of the incentives to publish across sectors.

Finally, our paper also entails some policy implications regarding the use of publication-based indicators to provide additional perspectives on firm's R\&D activities. The R\&D process in the private sector has been extensively examined on the basis of financial indicators or patents. Patents, in particular, have played a prominent role, and have been widely used to provide insights on which technologies firms developed, the novelty of these technologies, and their impact on subsequent technological developments (e.g. Hausman et al., 1984; Trajtenberg, 1990). However, "[...] patents do not always work in practice as they do in theory [...] appropriability is not perfect" (Levin et al., 1987, p. 784). As a result, patent data do not comprehensively capture a firm's efforts to build a competitive advantage on the basis of its scientific and technological advancements. Our paper demonstrates not only that firms produce a considerable amount of scientific publications, but also that publishing is a core element of a firm's R\&D strategy and management. In addition, the rich bibliographic details included in corporate publications data could reveal different aspects of firms' R\&D strategies (e.g. research collaborations, forms of open science or open innovation, IP strategies, selective revealing, diffusion of knowledge processes, etc.), which are not necessarily captured by more conventional measures of innovation. This suggests that the study of the R\&D process to inform policymakers should go beyond the more traditional R\&D metrics, such as financial and patent data, which could be complemented with publication-based indicators (Hopkins and Siepel, 2013).

Our study has some limitations that represent opportunity for future research on corporate publishing. First, we examine the magnitude and drivers of firms' involvement in the production of scientific publications. Yet our study does not provide fine-grained evidence of how the strength of firms' incentives to publish may vary by sectors. In line with previous works at individual level (e.g. McMillan and Deeds, 1998; Sauermann and Roach, 2014), survey analysis of firm researchers may provide direct evidence of the incentives that are at work in different sectors, how these interact with each other (complementary/substitution), and possibly the presence of incentives that are not considered by extant literature. Second, our study relies on 
a sample of large firms that are most active in terms of $R \& D$ investment. Although, these firms account for about $90 \%$ of global private R\&D investment in 2013, our sample does not include small- and medium-size firms (except where these are subsidiaries of the larger ones). Publishing could represent an important component of the R\&D efforts of these firms - it could work, for example, as a more cost-effective mechanism of IP protection than patenting. A limited number of studies examined firms' publication activity on the basis of samples of small- and mediumsize firms (e.g. Chai and Shih, 2016; Gök et al., 2015; Li et al., 2015). These studies provided important contributions to characterize small- and medium-size firms' publication activity. Yet, their analyses focused on single-sector samples of firms. As a result, there is a need for crosssectoral studies that can provide a more comprehensive understanding and characterization of what can lead small- and medium-size firms to publish and how their activity varies across sectors. Third, publication data may underestimate the contribution of firms to the production science. Firms may fund extra-mural research to influence the direction of research efforts (e.g. to stimulate collateral research) without necessarily co-authoring publications. A systematic analysis of the information reported in 'funding acknowledgments' and 'disclosure of conflicts of interests' sections can provide some indication of the extent to which firms' involvement in publications goes beyond co-authorship (Grassano et al., 2017). Finally, we relied on WoS to map firms' publications activity. As previous bibliometric research has pointed out, current publication databases may inevitably introduce biases in terms of the types of research output (for example, our study may underestimate the publication production in Software \& Computer Services given the relatively limited coverage of WoS of conference and workshop proceedings), as well as research field and language biases as a result of the journals indexed in the selected database.

\section{Concluding remarks}

This paper sheds light on the phenomenon of corporate publishing. We address the why do firms publish question by proposing a framework of different types of incentives for firms to contribute scientific publications. These are (i) accessing external knowledge and resources; (ii) attracting and retaining researchers; (iii) signalling and reputation building; (iv) supporting IP (intellectual property) strategies; and (v) supporting commercialization strategies. We then provide empirical evidence that the magnitude of corporate publishing is remarkable. The 
number of publications firms contributed to has grown between 2011 and 2015, although at a lower pace than the expansion of the total scientific publication output. Firms also contribute to highly cited publications more than expected and often co-author with researchers based at academic institutions. We also address the how does firms' engagement in publishing differ across sectors? demonstrating that corporate publishing is characterized by considerable heterogeneity within and across sectors.

Our analysis also suggests that the strength of incentives for firms to publish is likely to vary by sector. Combing the two contributions discussed above, we propose a taxonomy for four types of sectors. Quadrant I and Quadrant III of Figure 2 identify sectors that are characterized by levels of R\&D intensity and publication intensity, both of which are either high (Quadrant I) or low (Quadrant III). Sectors in Quadrant I (e.g. Pharmaceutical \& Biotechnology) have been the subject of much research into their publication activities, thus describing a 'paradigm' where the more a firm is engaged in R\&D activities the more the firms is expected to be involved in the production of scientific publications. However, the corporate publishing model that has emerged from these research efforts is not representative of a broader range of sectors and of the incentives to publish that are at work in these sectors. Our analysis demonstrates that there are two groups of sectors that represent a different 'paradigm'. Sectors in Quadrant II of Figure 2 (e.g. Oil \& Gas, Alternative Energy) are characterized by similar levels of publication intensity of sectors in Quadrant I, but by much lower levels of R\&D intensity. This suggests that firms' incentives to publish are likely to be stronger (or stronger than incentives to non-disclosure and patenting) in sectors in Quadrant II than in sectors in Quadrant I. Conversely, incentives to publish are likely to be weaker in the case of sectors in Quadrant IV (e.g. Electronic \& Electrical Equipment), where we observe much lower levels of publication intensity when compared to sectors in Quadrant I, although the levels of R\&D intensity are comparable.

This research has revealed a number of interesting opportunities for further research on corporate publishing. Studies at the level of firm researchers (e.g. survey analysis) can provide more fine-grained evidence of the relative strength of firms' incentives to publish across different industrial sectors. Also, publishing could be a particularly important activity for small- and medium-size firms, which may lack the necessary resources to pursue other strategies of IP protection (e.g. patenting) or knowledge access (e.g. alliances).

In summary, our paper provides evidence that firms make a considerable contribution to science and that publishing is an important component of the R\&D efforts of many firms. This 
phenomenon is, however, characterized by high levels of heterogeneity both across and within sectors. Explaining this heterogeneity represents an important avenue for future research and input for policy initiatives aimed at promoting science, technological change, and innovation.

\section{Acknowledgements}

We acknowledge the support of the IRITEC project, Unit B3 - Directorate B-JRC, European Commission. Daniele Rotolo also acknowledges the support of the European Research Council (ERC) under the European Union's H2020-EU.1.1. - Excellent Science, Grant \#716689: "Screening for cancer in the post-genomic era: diagnostic innovation and biomedicalisation in comparative perspective". We are grateful to Michele Cincera, Chiara Franzoni, Michael Hopkins, Daniel Vertesy, Ohid Yaqub and the two anonymous referees of the SPRU Working Paper Series (SWPS) for their comments, criticisms and suggestions on previous versions of this paper. The paper also builds on the feedback we have received from the participants of the 2017 CONCORDI Conference (Seville, Spain), 2017 Conference of the Italian Association of Management Engineering (Bari, Italy), the 2018 Schumpeter Society Conference (Seoul, South Korea), and 2018 Science and Technology Indicators Conference (Leiden, The Netherlands). We thank Richard Duffy, Joshua Hutton, and Jack Low for their research assistance. We are grateful to Ralph Napoletano for his support to finalise the first draft of this paper. The views expressed in the report are those of the authors and may not represent the views of the funder.

\section{References}

Alexy, O., George, G., and Salter, A. J. (2013). Cui bono? The selective revealing of knowledge and its implications for innovative activity. Academy of Management Review, 38(2):270-291.

Almeida, P., Hohberger, J., and Parada, P. (2011). Individual scientific collaborations and firm-level innovation. Industrial and Corporate Change, 20(6):1571-1599.

Archambault, É. and Larivière, V. (2011). Scientific publications and patenting by companies: a study of the whole population of Canadian firms over 25 years. Science and Public Policy, $38(4): 269-278$.

Arora, A., Belenzon, S., and Patacconi, A. (2018). The decline of science in corporate R\&D. Strategic Management Journal, 39(1):3-32.

Arora, A., Belenzon, S., and Sheer, L. (2017). Back to Basics: Why do Firms Invest in Research? NBER Working Paper Series.

Audretsch, D. B. and Feldman, M. P. (1996). R\&D spillovers and the geography of innovation and production. The American Economic Review, 86(3):630-640. 
Azoulay, P. (2002). Do pharmaceutical sales respond to scientific evidence? Journal of Economics $\&$ Management Strategy, 11(4):551-594.

Baker, S. and Mezzetti, C. (2005). Disclosure as a strategy in the patent race. The Journal of Law and Economics, 48(1):173-194.

Bar, T. (2006). Defensive publications in an R\&D race. Journal of Economics 83 Management Strategy, 15(1):229-254.

Bar-Gill, O. and Parchomovsky, G. (2003). The value of giving away secrets. Virginia Law Review, 89(8):1857-1895.

Barrett, B. (2002). Defensive use of publications in an intellectual property strategy. Nature biotechnology, 20(2):191-193.

Belenzon, S. and Patacconi, A. (2014). How does firm size moderate firms' ability to benefit from invention? Evidence from patents and scientific publications. European Management Review, 11(1):21-45.

Bergenholtz, C. (2014). Second-hand signals: How and why firms are being referenced in scientific publications. European Management Review, 11(2):159-171.

Boyack, K. W., Klavans, R., and Börner, K. (2005). Mapping the backbone of science. Scientometrics, 64(3):351-374.

Bromfield, T. and Barnard, H. (2010). The evolution of the intellectual property management strategy of an emerging multinational: Learning the purpose of patenting and scientific publications. IEEE Transactions on Engineering Management, 57(1):118-131.

Cassiman, B., Veugelers, R., and Zuniga, P. (2008). In search of performance effects of (in)direct industry science links. Industrial and Corporate Change, 17(4):611-646.

Chai, S. and Shih, W. (2016). Bridging science and technology through academicindustry partnerships. Research Policy, 45(1):148-158.

Cockburn, I. and Henderson, R. (1998). Absorptive capacity, coauthoring behavior, and the organization of research in drug discovery. Journal of Industrial Economics, 46(2):157-182.

Cohen, W. M. and Levinthal, D. (1990). Absorptive capacity: A new perspective on learning and innovation. Administrative Science Quarterly, 35(1):128-152.

Colson, T. J. (2001). Leveraging the power and value of intellectual property. Ivey Business Journal, 65(6):29.

Csomós, G. (2017). Mapping spatial and temporal changes of global corporate research and development activities by conducting a bibliometric analysis. Quaestiones Geographicae, 36(1):65-77.

Csomós, G. and Tóth, G. (2016). Exploring the position of cities in global corporate research and development: A bibliometric analysis by two different geographical approaches. Journal of Informetrics, 10(2):516-532.

Darby, M. R., Liu, Q., and Zucker, L. G. (1999). Stakes and stars: The effect of intellectual human capital on the level and variability of high-tech firms' market values. NBER Working Paper Series, No. 7201.

de Solla Price, D. J. (1963). Little Science, Big Science. Columbia University Press, New York, NY, USA. 
Della Malva, A. and Hussinger, K. (2012). Corporate science in the patent system: An analysis of the semiconductor technology. Journal of Economic Behavior 63 Organization, 84(1):118-135.

D'Este, P. (2005). How do firms' knowledge bases affect intra-industry heterogeneity? Research Policy, 34(1):33-45.

Ding, W. W. (2011). The impact of founders' professional-education background on the adoption of open science by for-profit biotechnology firms. Management Science, 57(2):257-273.

Eisenberg, R. S. (2000). The promise and perils of strategic publication to create prior art: A response to Professor Parchomovsky. Michigan Law Review, 98(7):2358.

Erden, Z., Klang, D., Sydler, R., and von Krogh, G. (2015). How can we signal the value of our knowledge? Knowledge-based reputation and its impact on firm performance in science-based industries. Long Range Planning, 48(4):252-264.

Fanelli, D. and Larivière, V. (2016). Researchers' individual publication rate has not increased in a century. PLOS ONE, 11(3):e0149504.

Fini, R. and Lacetera, N. (2010). Different yokes for different folks: Individual preferences, institutional logics, and the commercialization of academic research. In Libecap, G., Thursby, M., and Hoskinson, S., editors, Spanning Boundaries and Disciplines: University Technology Commercialization in the Idea Age, Advances in the Study of Entrepreneurship, Innovation and Economic Growth, Vol. 21, pages 1-25. Emerald Group Publishing, Bingley, UK.

Fleming, L. and Sorenson, O. (2004). Science as a map in technological search. Strategic Management Journal, 25(8-9):909-928.

Franzoni, C. and Scellato, G. (2010). The grace period in international patent law and its effect on the timing of disclosure. Research Policy, 39(2):200-213.

Frederiksen, L. F. (2004). Disciplinary determinants of bibliometric impact in Danish industrial research: Collaboration and visibility. Scientometrics, 61(2):253-270.

Friesike, S., Widenmayer, B., Gassmann, O., and Schildhauer, T. (2015). Opening science: towards an agenda of open science in academia and industry. Journal of Technology Transfer, 40(4):581-601.

Furukawa, R. and Goto, A. (2006). The role of corporate scientists in innovation. Research Policy, 35(1):24-36.

Gans, J. S., Murray, F. E., and Stern, S. (2017). Contracting over the disclosure of scientific knowledge: Intellectual property and academic publication. Research Policy, 46(4):820-835.

Gittelman, M. and Kogut, B. (2003). Does good science lead to valuable knowledge? Biotechnology firms and the evolutionary logic of citation patterns. Management Science, 49(4):366-382.

Godin, B. (1996). Research and the practice of publication in industries. Research Policy, 25(4):587-606.

Gök, A., Waterworth, A., and Shapira, P. (2015). Use of web mining in studying innovation. Scientometrics, 102(1):653-671.

Grassano, N., Rotolo, D., Hutton, J., Lang, F., and Hopkins, M. M. (2017). Funding data from publication acknowledgements: Coverage, uses and limitations. Journal of the Association for Information Science and Technology, 68(4):999-1017. 
Griliches, Z. (1979). Issues in assessing the contribution of research and development to productivity growth. The Bell Journal of Economics, 10(1):92-116.

Halperin, M. R. and Chakrabarti, A. K. (1987). Firm and industry characteristics influencing publications of scientists in large American companies. RED Management, 17(3):167-173.

Harhoff, D. (1996). Strategic spillovers and incentives for research and development. Management Science, 42(6):907-925.

Hausman, J., Hall, B. H., and Griliches, Z. (1984). Econometric models for count data with an application to the patents-R\&D relationship. Econometrica, 52(4):909-938.

Hayter, C. S. and Link, A. N. (2018). Why do knowledge-intensive entrepreneurial firms publish their innovative ideas? Academy of Management Perspectives, 32(1):141-155.

Hess, A. M. and Rothaermel, F. T. (2011). When are assets complementary? Star scientists, strategic alliances, and innovation in the pharmaceutical industry. Strategic Management Journal, 32(8):895-909.

Hicks, D. (1995). Published papers, tacit competencies and corporate management of the public/private character of knowledge. Industrial and Corporate Change, 4(2):401-424.

Hicks, D., Ishizuka, T., Keen, P., and Sweet, S. (1994). Japanese corporations, scientific research and globalization. Research Policy, 23(4):375-384.

Hicks, D., Wouters, P., Waltman, L., De Rijcke, S., and Rafols, I. (2015). Bibliometrics: The Leiden Manifesto for research metrics. Nature, 520(7548):429-431.

Hicks, D. M., Isard, P. A., and Martin, B. R. (1996). A morphology of Japanese and European corporate research networks. Research Policy, 25(3):359-378.

Hopkins, M. M. and Siepel, J. (2013). Just how difficult can it be counting up R\&D funding for emerging technologies (and is tech mining with proxy measures going to be any better)? Technology Analysis \& Strategic Management, 25(6):655-685.

Jaffe, A. B. (1986). Technological opportunity and spillovers of R\&D: Evidence from firms' patents, profits, and market value. American Economic Review, 76(5):984-1001.

Johnson, J. P. (2014). Defensive publishing by a leading firm. Information Economics and Policy, 28(1):15-27.

Jong, S. and Slavova, K. (2014). When publications lead to products: The open science conundrum in new product development. Research Policy, 43(4):645-654.

Kinney, A. J., Krebbers, E., and Vollmer, S. J. (2004). Publications from industry. Personal and corporate incentives. Plant Physiology, 134(1):11-15.

Larivière, V., Macaluso, B., Mongeon, P., Siler, K., and Sugimoto, C. R. (2018). Vanishing industries and the rising monopoly of universities in published research. PLOS ONE, 13(8):e0202120.

Levin, R. C., Klevorick, A. K., Nelson, R. R., Winter, S. G., Gilbert, R., and Griliches, Z. (1987). Appropriating the returns from Industrial Research and Development. Brookings Papers on Economic Activity, 1987(3):783-831.

Leydesdorff, L. and Bornmann, L. (2016). The operationalization of fields as WoS subject categories (WCs) in evaluative bibliometrics: The cases of library and information science and science \& technology studies. Journal of the Association for Information Science and Technology, 67(3):707-714. 
Leydesdorff, L. and Opthof, T. (2011). Remaining problems with the New Crown Indicator (MNCS) of the CWTS. Journal of Informetrics, 5(1):224-225.

Li, Y., Youtie, J., and Shapira, P. (2015). Why do technology firms publish scientific papers? The strategic use of science by small and midsize enterprises in nanotechnology. Journal of Technology Transfer, 40(6):1016-1033.

Lichtman, D., Baker, S., and Kraus, K. (2000). Strategic disclosure in the patent system. Vanderbilt Law Review, 53(6):2175-2217.

Liebeskind, J. P., Oliver, A. L., Zucker, L. G., and Brewer, M. B. (1996). Social networks, learning, and flexibility: Sourcing scientific knowledge in new biotechnology firms. Organization Science, 7(4):428-443.

Lim, K. (2004). The relationship between research and innovation in the semiconductor and pharmaceutical industries (19811997). Research policy, 33(2):287-321.

Liu, C. C. and Stuart, T. (2014). Positions and rewards: The allocation of resources within a science-based entrepreneurial firm. Research Policy, 43(7):1134-1143.

Mansfield, E. (1968). Industrial Research and Technological Innovation. Longmans, Green and Co., London.

McMillan, G. and Deeds, L. (1998). The role of reputation in the recruitment of scientists. RESD Management, 28(4):299-304.

McMillan, G. S., Klavans, R. A., and Hamilton, R. D. (1995). Firm management of scientific information: some predictors and implications of openness versus secrecy. R\&BD Management, 25(4):411-419.

Merges, R. P. (2004). A new dynamism in the public domain. University of Chicago Law Review, 71(1):183-203.

Miles, M. B., Huberman, A. M., and Saldaña, J. (1994). Qualitative Data Analysis an Expanded Sourcebook. Sage Publications, Thousand Oaks.

Mukherjee, A. and Stern, S. (2009). Disclosure or secrecy? The dynamics of Open Science. International Journal of Industrial Organization, 27(3):449-462.

Muller, P. and Pénin, J. (2006). Why do firms disclose knowledge and how does it matter? Journal of Evolutionary Economics, 16(1-2):85-108.

Murray, F. (2004). The role of academic inventors in entrepreneurial firms: sharing the laboratory life. Research Policy, 33(4):643-659.

Narin, F. and Rozek, R. P. (1988). Bibliometric analysis of U.S. pharmaceutical industry research performance. Research Policy, 17(3):139-154.

Nelson, R. R. (1990). Capitalism as an engine of progress. Research Policy, 19(3):193-214.

Okubo, Y. and Sjüberg, C. (2000). The changing pattern of industrial scientific research collaboration in Sweden. Research Policy, 29(1):81-98.

Olmeda-Gómez, C., Ovalle-Perandones, M. A., and de Moya-Anegón, F. (2015). Analysis of research collaboration between universities and private companies in Spain based on joint scientific publications. Information Research, 20(4):67-84.

Parchomovsky, G. (2000). Publish or perish. Michigan Law Review, 98(4):926-952. 
Parish, A. J., Boyack, K. W., and Ioannidis, J. P. A. (2018). Dynamics of co-authorship and productivity across different fields of scientific research. PLOS ONE, 13(1):e0189742.

Pavitt, K. (1984). Sectoral patterns of technical change: Towards a taxonomy and a theory. Research Policy, 13(6):343-373.

Pellens, M. and Della Malva, A. (2018). Corporate science, firm value, and vertical specialization: Evidence from the semiconductor industry. Industrial and Corporate Change, 27(3):489-505.

Penders, B. and Nelis, A. P. (2011). Credibility engineering in the food industry: Linking science, regulation, and marketing in a corporate context. Science in Context, 24(4):487-515.

Pénin, J. (2007). Open knowledge disclosure: An overview of the evidence and economic motivations. Journal of Economic Surveys, 21(2):326-348.

Polidoro, F. (2013). The competitive implications of certifications: The effects of scientific and regulatory certifications on entries into new technical fields. Academy of Management Journal, 56(2):597-627.

Polidoro, F. and Theeke, M. (2012). Getting competition down to a science: The effects of technological competition on firms' scientific publications. Organization Science, 23(4):11351153.

Pudovkin, A. I. and Garfield, E. (2002). Algorithmic procedure for finding semantically related journals. Journal of the American Society for Information Science and Technology, 53(13):1113-1119.

Rafols, I., Hopkins, M. M., Hoekman, J., Siepel, J., O’Hare, A., Perianes-Rodríguez, A., and Nightingale, P. (2014). Big Pharma, little science? Technological Forecasting and Social Change, 81(January):22-38.

Rafols, I. and Leydesdorff, L. (2009). Content-based and algorithmic classifications of journals: Perspectives on the dynamics of scientific communication and indexer effects. Journal of the American Society for Information Science and Technology, 60(9):1823-1835.

Rappa, M. A. and Debackere, K. (1992). Technological communities and the diffusion of knowledge. RESD Management, 22(3):209-220.

Rinner, T. E. (2003). Protecting minor improvements on core patents: Complementing traditional patent protection with strategic disclosure. The John Marshall Review of Intellectual Property Law, 2(2):398.

Rosenberg, N. (1990). Why do firms do basic research (with their own money)? Research Policy, 19(2):165-174.

Rotolo, D. and Camerani, R. (2017). Scientific publication activity of 2014 Scoreboard Companies. Technical report, SPRU-University of Sussex (Brighton, UK) for IPTS, JRC, European Commission.

Sauermann, H. and Roach, M. (2014). Not all scientists pay to be scientists: PhDs' preferences for publishing in industrial employment. Research Policy, 43(1):32-47.

Sauermann, H. and Stephan, P. (2012). Conflicting logics? A multidimensional view of industrial and academic science. Organization Science, 24(3):889-909.

Schubert, A. and Braun, T. (1986). Relative indicators and relational charts for comparative assessment of publication output and citation impact. Scientometrics, 9(5):281-291. 
Simeth, M. and Cincera, M. (2016). Corporate science, innovation, and firm value. Management Science, 62(7):1970-1981.

Simeth, M. and Raffo, J. D. (2013). What makes companies pursue an Open Science strategy? Research Policy, 42(9):1531-1543.

Sismondo, S. (2012). Medical publishing and the drug industry: is medical science for sale? Learned Publishing, 25(1):7-15.

Smith, R., Jefferson, T., Frizelle, F., Haug, C., and Hoey, J. (2005). Medical journals are an extension of the marketing arm of pharmaceutical companies. PLoS Medicine, 2(5):e138.

Spencer, J. W. (2001). How relevant is university-based scientific research to private hightechnology firms? A United States-Japan comparison. Academy of Management Journal, 44(2):432-440.

Stephan, P. E. (1996). The economics of science. Journal of Economic Literature, 34(3):11991235.

Stern, S. (2004). Do scientists pay to be scientists? Management Science, 50(6):835-853.

Sternitzke, C. (2010). Knowledge sources, patent protection, and commercialization of pharmaceutical innovations. Research Policy, 39(6):810-821.

Sun, Y., Negishi, M., and Nishizawa, M. (2007). Coauthorship linkages between universities and industry in Japan. Research Evaluation, 16(4):299-309.

Tijssen, R. J. (2009). Internationalisation of pharmaceutical R\&D: How globalised are Europe's largest multinational companies? Technology Analysis 83 Strategic Management, 21(7):859879 .

Tijssen, R. J. W. (2004). Is the commercialisation of scientific research affecting the production of public knowledge?: Global trends in the output of corporate research articles. Research Policy, 33(5):709-733.

Tijssen, R. J. W., van Leeuwen, T. N., and Korevaar, J. C. (1996). Scientific publication activity of industry in the Netherlands. Research Evaluation, 6(2):105-119.

Trajtenberg, M. (1990). A penny for Your quotes: Patent citations and the value of innovations. The RAND Journal of Economics, 21(1):172-187.

van Eck, N. J., Waltman, L., van Raan, A. F. J., Klautz, R. J. M., and Peul, W. C. (2013). Citation analysis may severely underestimate the impact of clinical research as compared to basic research. PLoS ONE, 8(4):e62395.

Waltman, Ludo; Van Eck, N. J. (2012). A new methodology for constructing a publication-level classification system of science. Journal of the American Society for Information Science and Technology, 63(12):2378-2392.

Wang, Q. and Waltman, L. (2016). Large-scale analysis of the accuracy of the journal classification systems of Web of Science and Scopus. Journal of Informetrics, 10(2):347-364.

Wuchty, S., Jones, B. F., and Uzzi, B. (2007). The increasing dominance of teams in production of knowledge. Science, 316(5827):1036-9.

Zucker, L. G., Darby, M. R., and Armstrong, J. S. (2002). Commercializing knowledge: university science, knowledge capture, and firm performance in biotechnology. Management Science, 48(1):138-153. 


\section{JRC Mission}

As the science and knowledge service of the European Commission, the Joint Research Centre's mission is to support EU policies with independent evidence throughout the whole policy cycle.

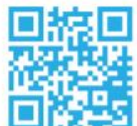

EU Science Hub

ec.europa.eu/jrc

y @EU_ScienceHub

f EU Science Hub - Joint Research Centre

in Joint Research Centre

Yuon EU Science Hub 